Author Queries:

\title{
Comments:
}

[COM 1]This is the correct Funding Information.

Verso running head: M. KALTSA ET AL.

Recto running head: INTERNATIONAL JOURNAL OF BILINGUAL EDUCATION AND BILINGUALISM

Copyright Line: @ 2017 Informa UK Limited, trading as Taylor \& Francis Group

License:

\section{Language external and language internal factors in the acquisition of gender: the case of Albanian-Greek and English-Greek bilingual children}

\author{
Maria Kaltsa $^{\mathrm{a}} \quad$, Alexandra Prentza $^{\mathrm{b}}$, Despina Papadopoulou ${ }^{\mathrm{c}}$ and lanthi Maria Tsimpli[AQ2] ${ }^{\mathrm{d}}$ \\ aDepartment of Theoretical \& Applied Linguistics, School of English, Faculty of Philosophy, Aristotle University of \\ Thessaloniki, Thessaloniki, Greece[AQ3] \\ ${ }^{b}$ Department of Linguistics, School of Philology, Faculty of Philosophy, University of loannina, loannina, Greece \\ CDepartment of Linguistics, School of Philology, Faculty of Philosophy, Aristotle University of Thessaloniki, Thessaloniki, \\ Greece \\ dDepartment of Theoretical and Applied Linguistics, Faculty of Modern \& Medieval Languages, University of Cambridge, \\ Cambridge, UK \\ CONTACT Maria Kaltsa mkaltsa@enl.auth.gr[AQ4]
}

(Received 13 June 2017; Accepted 16 June 2017)

\begin{abstract}
The aim of this experimental study is to examine the development of gender assignment and gender agreement in bilingual Albanian-Greek and English-Greek children as well as the exploitation of gender cues on the noun ending in real and pseudo-nouns. Four gender tasks were designed, two targeting gender assignment (determiner + noun production) and two gender agreement (predicate adjective production). Performance is investigated in relation to the role of (positive) L1 transfer (Albanian vs. English), the role of the bilingual's vocabulary knowledge in Greek as well the role of input factors including the monolingual/bilingual school contexts and the role of parental education as a proxy for socioeconomic status (SES). The results show a strong interaction between the bilinguals' performance and their Greek vocabulary development and a negative link between gender accuracy and use of the other language.
\end{abstract}

KEYWORDS: Bilingualism; gender; Greek; English; Albanian; input effects

\section{Introduction[AQ11]}

This study investigates the development of gender assignment and agreement in bilingual Albanian-Greek and English-Greek children by examining the role of input related factors, i.e. age of onset (i.e. amount of exposure), home language, early and current (bi)-literacy, monolingual or bilingual schooling, oral language use, vocabulary dominance and L1. Gender is a language-specific feature realized in Greek and Albanian but not in English (with the exception of pronouns in singular). In these languages, gender is a lexical property of the noun and, thus, gender is assigned in the lexicon, while determiners and adjectives bear a gender value through agreement with the noun. Drawing on data from gender assignment/agreement with real and pseudo-nouns, this experimental study addresses the role of (a) L1 transfer effects (Albanian vs. English) in the acquisition of gender in Greek (L2), (b) proficiency in L2 Greek and the way it is affected by monolingual/bilingual school contexts and (c) socioeconomic status (SES) measured in our study in terms of level of parental education, as an indication of the quality/quantity of input a bilingual child receives.

In the following section (Section 2) we review studies on bilingual gender acquisition, particularly, findings on factors affecting gender. Section 3 outlines the gender system in Greek ${ }^{1}$ and Albanian and discusses research on monolingual child acquisition of gender in each language. In section 4 we describe the method as well as the results of our study and in section 5 we discuss our findings.

\section{Gender acquisition in bilingual children}

In the child bilingualism literature, the quantitative and qualitative properties of input have been associated with the acquisition of lexical and morphosyntactic features such as gender. Although bilingual children have to divide their language input 
between two languages due to time spent using both languages, they, nevertheless, have been shown to follow the same developmental steps as monolingual children (e.g. Genesee and Nicoladis 2007). Measures of input quantity have been used to explain variation in vocabulary development in the L1 and the L2 (Cobo-Lewis etal. 2002;[AQ12][AQ13]or verbs see Blom 2010; Paradis 2010; Paradis 2011, for the mass/count distinction see Gathercole 2002a) along with variation in other grammatical phenomena (for grammatical gender see Gathercole 2002b; Montrul and Potowski 2007; Unsworth etal. 2014) or the overall development of grammatical abilities (Jia and Fuse 2007; Chondrogianni and Marinis 2011). The age of bilingual children, however, is a factor that also needs to be considered. For instance, Gathercole's study (2002c) which tested 10 year old Spanish-English bilinguals suggests that the frequency of a particular linguistic property in the input plays a greater role in the early years, i.e. until children have reached an adequate mass of input for the relevant property (cf. Tsimpli 2014). Meanwhile, findings on the role of home language use are contradictory; some studies report positive effects of extensive use of the minority language at home (De Houwer 2007; La Morgia 2011), while others report no effects (Goldberg, Paradis, and Crago 2008; Paradis 2011) or very restricted ones highlighting the role of the number of different speakers of the minority language in the child's environment (Place and Hoff 2011). Another factor positively correlating to the amount and type of language exposure is SES, often measured in terms of levels of parent education. Research has shown that high levels of SES impact positively on the overall linguistic growth of bilingual children, and particularly on the rate of language acquisition as well as on the size of bilingual children's vocabularies (Armon-Lotem, Walters, and Gagarina 2011; Paradis 2011).

As regards biliteracy, i.e. literacy in both $L 1$ and $L 2$, research has shown that this factor is a determinant of general language growth. Specifically, Rauch etal. (2012) t[AQ14]ested 299 German and Turkish-German secondary school students and found that biliterate bilingual students outperformed monolingual and partially biliterate students in both L3 reading proficiency and in metalinguistic awareness. However, to the best of our knowledge biliteracy has not been shown yet to impact on the development of a specific grammatical feature.

Another factor examined in bilingual acquisition is language dominance. Researchers have noted that there is a considerable diversity in the selection of language measures that are appropriate to determine dominance (Hulstijn 2010).[AQ15] This observation reflects the assumption that in bilingualism literature dominance reflects many dimensions of language use and experience (Gertken, Amengual, and Birdsong 2014). Objective measures of dominance however provide an alternative that could minimize subjectivity. To this end, in the current study language dominance has been examined as vocabulary dominance decided on the basis of the comparison between the sizes of the two languages' vocabularies. (for studies that used proficiency as an indicator of dominance see Kupisch 2007 and Unsworth 2016 as well as Montrul 2016 for an overview).

Since the amount of language exposure has been observed to affect the linguistic development of bilingual children, the present study aims to identify the input measures that better predict the acquisition of gender. By input measures we refer to a variety of information on oral and written language exposure for each bilingual. As is outlined in section 4.2 in more detail, for the purposes of this study input measures are broken up into current and past exposure to each language, as well as into oral language use and literacy.

Earlier studies on gender show that although simultaneous bilingual children might show a delay in development, they nevertheless make the same types of errors as monolinguals (Müller 1990; Kupisch, Müller, and Cantone 2002). Other findings reveal that instead of a delay, bilinguals show acceleration in development in one of their L1s (Cornips and Hulk 2006). Additionally, age of onset has been identified as a contributing factor to the development of gender accuracy. Specifically, Meisel's (2009) data suggest that determiner gender marking in sequential bilingual children with first exposure to French at age 3;7 differed compared to simultaneous bilinguals, with the latter group performing significantly better. Similar findings are reported by Carroll (1989) who identifies age 5 as critical for the acquisition of gender in the L2 of bilingual individuals. Recent elicited gender production data from Unsworth etal. (2014) showed that gender agreement errors are found in sequential bilinguals but not in simultaneous bilinguals who are indistinguishable from monolinguals. Meanwhile, restricted amount of input, even if the age of onset to both languages is the time of birth, leads to gender marking errors. Gathercole (2002b) also reports that the children with the least input take the longest to acquire gender marking in Determiner-Noun constructions.

Moreover, the literature distinguishes among early and current amount of exposure and amount of exposure over time. Current amount of exposure and amount of exposure over time but not amount of exposure in the early years have been shown to be significant predictors of gender development (Gathercole and Thomas 2005; Unsworth etal. 20124;[AQ16] Unsworth 2013).

Gender development has also been shown to be affected by language proficiency. In Unsworth etal. (2014), English-Greek bilingual children's performance on grammatical gender was predicted by measures of cumulative exposure to input but also by vocabulary knowledge. For masculine and feminine nouns both input and vocabulary knowledge were predictive factors while for neuter nouns it was vocabulary alone that predicted two-thirds of the variance in the data. In Unsworth etal. (2014) gender assignment was also examined in Dutch in bilingual English-Dutch children. Although gender accuracy was better in Greek than in Dutch, performance on Dutch gender was primarily predicted by input factors. The more predictive role of vocabulary in Greek as opposed to Dutch gender was partly attributed to the fact that Greek nouns carry gender cues on their endings, which, in the majority of cases are highly reliable (Mastropavlou and Tsimpli 2011, see also section 3.1). In contrast, Dutch nouns carry little or no gender information that can be used for gender assignment. Thus, information on gender is primarily encoded/decoded in the process of syntactic processing of the Dutch DP given that there are specific, and limited, contexts which provide unambiguous cues for gender assignment in this language.

Bilingual gender acquisition research has also addressed the issue of crosslinguistic influence, which has been proposed to be subject to restrictions of directionality, and/or particular language domain investigated (Paradis and Genesee 1996; Müller 1998; Müller and Hulk 2001). Data from German-Italian simultaneous bilinguals show that the simultaneous acquisition of a language like Italian accelerates the acquisition of determiners in German; the lower complexity of the determiner system and the higher token-frequency of determiner-noun sequences in Italian facilitate acquisition in German (Kupisch 2005). As regards adjective-noun gender agreement, Noicoladis (2006) t[AQ17]ested English-French bilingual children on AdjectiveNoun strings in French and observed that the bilingual children were more accurate than their monolingual peers. Cornips, van der Hoek, and Verwer (2006) examined possible crosslinguistic effects in the acquisition of determiner-noun, adjective-noun and relative pronoun-noun agreement by bilingual Dutch-Moroccan and Dutch-Turkish children. Moroccan-Arabic instantiates a gender distinction, while Turkish does not. Results showed that the Dutch-Moroccan group is overall more accurate than the Dutch-Turkish group, a result showing a positive L1 transfer. However, no acceleration effect was found when compared to monolingual children.

Considering these diverse findings, the present study aims to examine how language internal factors (vocabulary proficiency) interact with language external ones (input measures) in in the production of gender in Albanian-Greek and English-Greek bilinguals. To this end, we address the independent role and any possible interaction of factors such as age of onset (simultaneous vs. early/late sequential bilinguals) and crosslinguistic transfer as well as factors like input (i.e. early and current exposure, oral and written input) and language proficiency measured in terms of lexical knowledge. 


\section{Greek and Albanian gender}

\subsection{Greek gender distinctions}

According to Corbett (1991), there is a three-way distinction, masculine, feminine or neuter, for gender encoding across languages. In languages that parametrize gender, grammatical gender is a lexical classification feature (cf. Chomsky 1995) and gender agreement between Determiner and Noun or between a Noun and an Adjective is a syntactic computation that involves a dependency of some form between an uninterpretable/unvalued gender feature on $D$ or Adj and its valued counterpart on N (Carstens 2000; Chomsky 2001; Bošković 2009a, 2009b; see Tsimpli and Hulk 2013 for a detailed account on Greek).

In Greek, Ralli (2002) suggests a three-way distinction of masculine, feminine and neuter with gender being a feature of the noun stem, while the suffix only reflects the gender value of the stem (cf. Tsimpli 2003; Hawkins and Tsimpli 2009). This feature establishes gender agreement and gender assignment on nominal and pronominal forms (see (1) to (3)). Gender runs through the entire nominal system in Greek and is evident on all nominal inflectional classes. For example, in (1) the determiner $O$ is marked for masculine gender, while the suffix -os denotes the masculine gender in as is the adjective oréos and the noun kipos ${ }^{2}:[\mathrm{AQ} 18]$

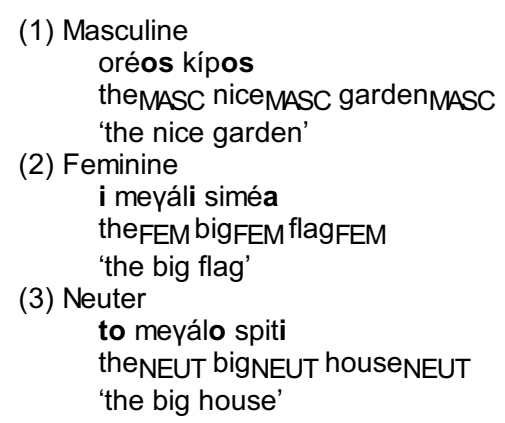

Previous studies on the acquisition of Greek suggest that gender is acquired by age 3;6 or even earlier by monolingual children (cf. Stephany 1997; Marinis 2003; Mastropavlou 2006; Stephany and Christofidou 2008). Neuter gender is more often overgeneralized and, thus, appears to be the default value, at least in some studies (see Tsimpli and Hulk 2013). For example, gender is more frequently overgeneralized by young monolinguals (Mastropavlou 2006) and L2 learners of Greek (Varlokosta 1995;[AQ19] Tsimpli 2003). Noun suffixes are cues for gender assignment in Greek (see examples (1)-(3). Their role in the elicited production of gender agreement with pseudo-nouns has been shown to be decisive in monolingual development. In particular, Varlokosta (2011) shows that 5-year old monolingual Greek children tested on the production of Determiner-Noun and Determiner-Adjective-Noun contexts show more accurate gender assignment with suffixes of high predictive values (-o, as, -is, -o) than with those of low (-i). ${ }^{3}$ Mastropavlou (2006) reports similar findings from 3-year olds who, however, rely less on the predictive values of the suffixes. This developmental pattern suggests that learner sensitivity to noun suffixes presupposes a certain length of exposure for predictive values to develop (for the predictive values of suffixes for Greek adults see Mastropavlou and Tsimpli 2011).

\subsection{Albanian gender distinction}

Albanian has a two-way gender distinction, masculine and feminine, marked on the determiner system (Kurani and Muho 2011; Revithiadou and Spyropoulos 2013; Kurani and Trifoni 2014). The use of the neuter is restricted to cases like 'theNEUT walking' (Gramatika e gjuhës shqipe, 2002) which correspond more closely to the use of neuter as a gender value exclusively used for 'default' contexts (cf. Tsimpli and Hulk 2013). As examples (4a) and (4b) illustrate, the definite determiner is a discontinuous element appearing both as a suffix marked for gender (-i for masculine, -a for feminine) on the noun ending and as a free morpheme also marked for gender (-i for masculine, -e for feminine). The noun and the adjective are also marked for gender. The indefinite article një is a free morpheme unmarked for gender; it appears undifferentiated in form with masculine and feminine DPs as shown in (5a) and (5b):

(4) Noun + Definite Definite + Adjective

a. Kopshtii bukur

GardenMASC the MASC the MASC nice MASC

'the nice garden'

b. Shtëpiae madhe

House FEM the FEM the FEM bigFEM

'the big house'

(5) Indefinite + Noun Definite + Adjective

a. Një kopst $i$ bukur

AMASC+FEMgardenMASC the MASC nice MASC

'a nice garden'

b. Një shtëpi e madhe

AMASC+FEMhouse FEM the FEM bigFEM

'a big house'

\section{The study}

\subsection{Experimental design}

To test the bilingual acquisition of grammatical gender in Greek, four tasks were designed, two targeting gender assignment and two gender agreement. In the gender assignment tasks, participants were asked to provide an agreeing definite or indefinite article $(D+N)$, while in the gender agreement tasks, they were asked to provide an agreeing predicate adjective. 
The determiner tasks comprised one real and one pseudo-noun task. The real noun task included 54 test items (animals or objects) and was carried out in three phases. Phase A familiarized participants with the test items; the children listened to all test words and looked at relevant pictures. Orthographic cues were also provided since words corresponding to each test item appeared on the computer screen. Phase B included three practice items and phase $C$ involved the actual testing. A picture of each item was presented on the computer screen and the participant was asked to provide the name of the animal/object by answering the question 'What is on the table?':

(6) a.ti íne páno sto trapézi?

what be 3 SING on the table

'What is on the table?'

b. éna/to vivlío

aNEUT/the NEUT bookNEUT

'A/the book.'

18 items were used for each of the three Greek gender values. The masculine and neuter values comprised 6 items for each of the three endings, i.e. [-as, -is, -os for masculine and $-m a,-i,-o$ for neuter], whereas the feminine value comprised 9 items for each of the two endings [- $a$ and -1$]$.

The pseudo-word task included 56 three-syllable penultimate accented test items. The same endings were used for each gender value, with 8 items for each ending [-as, -is, -os, -a, -i(spelled as $\eta$, feminine nouns only),-ma, -o]. The testing procedure was the following: in slide $A$ the participant saw the novel object and listened to as well as read the pseudo-noun. Next, s/he sees the novel object on a table and is asked the question '[AQ20]What is on the table?' An example of an anticipated response when the participant is given a pseudo-noun with a masculine suffix is the following:

\section{(7) énas/o krodotís} aMASC/the MASC krodotisMASC

All test items corresponded to the nominative singular form.

The adjective tasks included real adjectives predicating real and pseudo-nouns in two different tasks. The real noun task consisted of 54 test items and the pseudo-noun task of 56. The suffixes used per gender value, and the training part were the same as in the determiner tasks. However, in the adjective tasks, in each slide the participants were presented with two pictures of the same real or pseudo-noun that differed either in colour and/or size, an arrow pointing to one of the two items appeared on the slide and the participants were asked to answer the following question: 'What kind of X(item) is it?':

(8) a.ti vivlío íne? mikró

ti bookNEUT be 3 SING? small NEUT

'What kind of a book is it? Small.'

b.ti krodotís íne? prásinos.

ti krodotisMASC be 3 SING? greenMASC

'What kind of krodotis is it? Green.'

All responses were transcribed and accuracy scores per participant were calculated for the analysis. A score of one was assigned for each correct response and a score of 0 for an erroneous one. Correct responses were identified as follows: (a) in the assignment tasks, the use of a determiner agreeing in gender with the noun provided and (b) in the agreement tasks, the use of any adjective agreeing in gender with the noun provided.

\subsection{The participants}

The participants were 66 children from 8;0 to10;0 years of age. There were 23 Albanian-Greek bilinguals (15 girls, 8 boys. Mean age: 8;6, SD: 0;4) and 21 English-Greek bilinguals (6 girls, 15 boys. Mean age: 9;4 SD: 1;1). All children were Greek residents. The Albanian group attended state primary schools where Greek was the only medium of instruction. The English group attended a private international school where the hours of instruction in Greek ranged between 5 and $10 \mathrm{~h}$ per week while the hours of instruction in English were between 25 and $30 \mathrm{~h}$. Data was also collected from 22 Greek monolingual children who attended a state primary school (13 girls, 9 boys. Mean age: 9;1, SD: 0;6). Even though gender is acquired by the age of 3;6 years (Stephany 1997), the use of suffixes as gender cues is a strategy that develops later even for monolinguals, who appear to have not fully developed this by age 5.Notice that we have tested even older bilingual children to make sure they are literate in Greek, since they need to be aware of the word spelling, i.e. $-\eta$ (feminine) vs. $-I$ (neuter) while both are pronounced as [i], in order to decide on gender value.

Background information was collected on a number of input related variables with the use of questionnaires administered to parents and to children. Questionnaire data outlines the profile of our bilingual children and provides information on the specific input measures that constitute the experimental variables of the current study. Expressive vocabulary of bilingual children was also measured as it provides an independent measure of language proficiency in each of the languages the bilingual child speaks. As discussed in section 3.1 vocabulary development is closely related to gender development in Greek. Thus, language proficiency albeit linked to input effects, is examined separately in our study and constitutes another experimental variable. Information on all the experimental variables is presented in the following section.

\subsubsection{Language external factors}

Starting with age of onset, as one of the input variables, three different groups were formed: children exposed to both languages from birth up to age 3, identified as simultaneous bilinguals, from age 3 to age 6 as early sequential bilinguals and from age 6 onwards as late sequential bilinguals. To determine age of onset, the questionnaire included a question about the child's country of birth and a question about age of arrival to Greece if not born in the country. As shown, in Table 1, the distribution differs in the two groups $(F(1,43)=5.684, p<.05)$ as there are significantly more simultaneous and early sequential bilinguals in the Albanian-Greek than in the English-Greek group. 


\begin{tabular}{|l|c|c|}
\hline \multirow{2}{*}{ Age of Onset } & \multicolumn{2}{|c|}{ Groups } \\
\cline { 2 - 3 } & Albanian-Greek Bilinguals & English-Greek Bilinguals \\
\hline \hline Simultaneous & 71.4 & 26.1 \\
\hline \hline Early sequential & 28.8 & 39.1 \\
\hline \hline Late sequential & 4.8 & 34.8 \\
\hline
\end{tabular}

The Home Language measure refers to the children's exposure to each (Albanian, Greek \& English, Greek) and to both languages (Albanian/Greek, English/Greek) from birth up to the age of schooling, i.e. around 6. The relevant questions asked about the language(s) the child heard/used during the period from birth up to the age of 3 and between the ages of $3 a n d 6$ years old. Both bilingual groups were exposed to the other language more than to Greek or to both languages to the same time. However, as shown in Table 2, exposure to Greek is significantly higher for the Albanian-Greek than for the EnglishGreek group $(F(1,43)=7.042, p<.05)$.

Table 2. Home language (\%).

\begin{tabular}{|l|c|c|}
\hline \multirow{2}{*}{ Home Language } & \multicolumn{2}{|c|}{ Groups } \\
\cline { 2 - 3 } & Albanian-Greek Bilinguals & English-Greek Bilinguals \\
\hline \hline Albanian/English & 40 & 51 \\
\hline \hline Greek & 32 & 20 \\
\hline \hline Both & 28 & 29 \\
\hline
\end{tabular}

Another measure that was evaluated by means of the questionnaire was Early (Bi)literacy. Early (Bi)literacy measures focus on whether and to which language(s) the family members read books to the children. Data showed that (a) only half of the Albanian-Greek children and nearly all of the English-Greek children were read books at a young age with the between-group difference being significant $(F(1,43)=12.778, p=.001)$ and $(b)$ the choice of language differed in the two groups, in that bookreading was mostly in English for the English-Greek bilinguals and mostly in Greek or the Albanian-Greek bilinguals $(F(1,43)=$ $22.226, p<.001)$.

The Current (Bi)literacy measure aims to evaluate children's current language preference/use in writing/reading tasks. More specifically, the relevant questions asked about (a) whether the children take language classes in Albanian/English and (b) which language is their preferred one for daily writing/ reading tasks (writing lists/letters/cards, reading aloud, texting, emailing, visiting websites, video-gaming, book/magazine reading). As shown in Table 3, while all of the English-Greek bilinguals are literate in both languages, the majority of the Albanian-Greek bilinguals are literate only in Greek $(F(1,43)=127.491, p<.001)$

Table 3. Biliteracy (\%).

\begin{tabular}{|l|c|c|}
\hline Early (Bi)literacy & Albanian-Greek Bilinguals & English-Greek Bilinguals \\
\hline \hline English/Albanian & 11.6 & 54.8 \\
\hline \hline Greek & 24.6 & 32.5 \\
\hline \hline Both & 15.9 & 7.9 \\
\hline \hline Total & 52.1 & 95.2 \\
\hline \hline Current (Bi)literacy & & \\
\hline \hline Biliterate & 14.7 & 100 \\
\hline \hline Monoliterate & 82.6 & 0 \\
\hline \hline Total & 100 & 100 \\
\hline
\end{tabular}

The Current Language Use measure concerns the participants' daily language preference/use in oral tasks. The relevant questions asked about the children's preferred language for oral interaction with family members/friends, for memorizing phone numbers, telling the time, mental counting/calculating, watching TV/movies. As shown in Table 4, the Albanian bilinguals strongly preferred to use Greek $(F(1,43)=36.884, p<.001)$, in contrast to the English bilingual children. The groups also differed in the use of the 'other' language; the English-Greek group used English more than the Albanian-Greek group used Albanian $(F(1,43)=13.444, p=.001)$ 


\begin{tabular}{|l|c|c|}
\hline \multirow{2}{*}{ Current Language Use } & \multicolumn{2}{|c|}{ Groups } \\
\cline { 2 - 3 } & Albanian-Greek Bilinguals & English-Greek Bilinguals \\
\hline \hline Albanian/English & 21 & 41 \\
\hline \hline Greek & 38 & 9 \\
\hline \hline Both & 32 & 39 \\
\hline
\end{tabular}

This study also exploited the role of the Socioeconomic Status (SES) measured in terms of parents' educational background. An ordinal scale from 1 to 5 with ' 1 'assigned to primary education and ' 5 ' to university education was used. While most parents in the Albanian-Greek group are secondary school graduates, most parents in the English-Greek group are university educated with the difference between the groups being significant for both parents (Father's SES: $F(1,43)=65.665, p<.001$; Mother's SES: $F(1,43)=93.448, p<.001)$. Results are shown in Figure 1.

Figure 1. Parental SES - educational background.

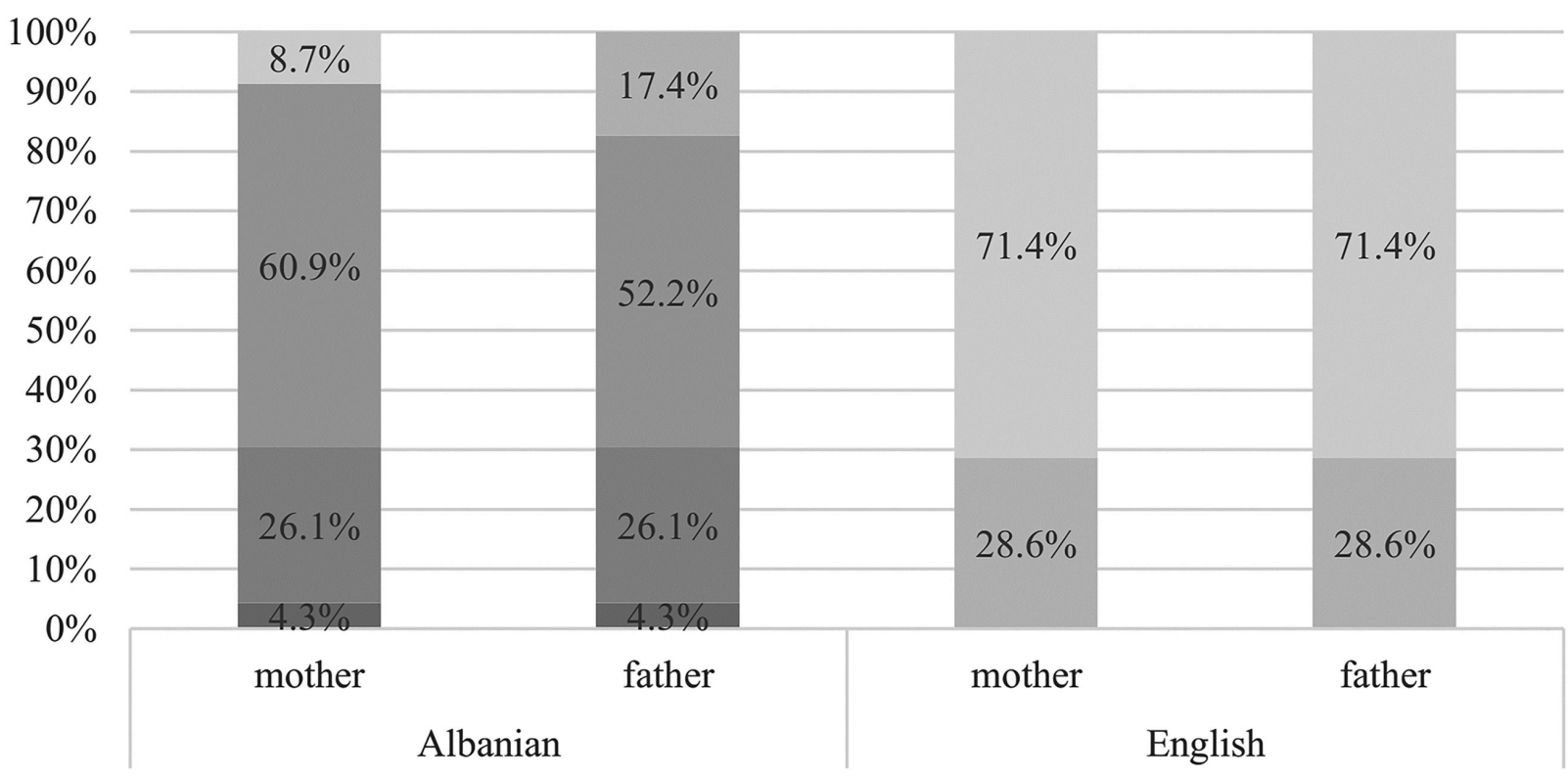

$\square$ primary $\square$ secondary $\square$ high school $\square$ tech-college $\square$ university

\subsubsection{Language internal factor: language proficiency}

The children's lexical abilities were measured by means of an expressive vocabulary test in Greek, standardized for monolingual Greek children (Vogindroukas, Protopapas, and Sideridis 2009), a standardized expressive vocabulary test in English (Renfrew 2001) and a similar vocabulary test in Albanian which has not been standardized as yet (Kapia and Kananaj 2013). Each vocabulary test contained 50 items. In particular, the children were presented with 50 black-and-white pictures, which they were asked to name. The participants' scores were used as independent measures of language proficiency in Greek and in Albanian/English. Between-group comparisons showed that the Albanian-Greek bilinguals (75.2\%, SD:14) fared significantly better in the Greek vocabulary test than the English-Greek bilinguals (56\%, SD:17.8); $F(1,42)=15.934, p<.001)$. Within-group comparisons revealed that while the Albanian-Greek group scores better in the Greek than in the Albanian vocabulary test $(F(1,22)=19.042, p<.001)$, the English-Greek group scores higher in the English than in the Greek vocabulary test $(F(1,20)=36.287, p<.001)$. Results are presented in Figure 2.

Figure 2. Group performance in Greek and Albanian/English vocabulary tests. 


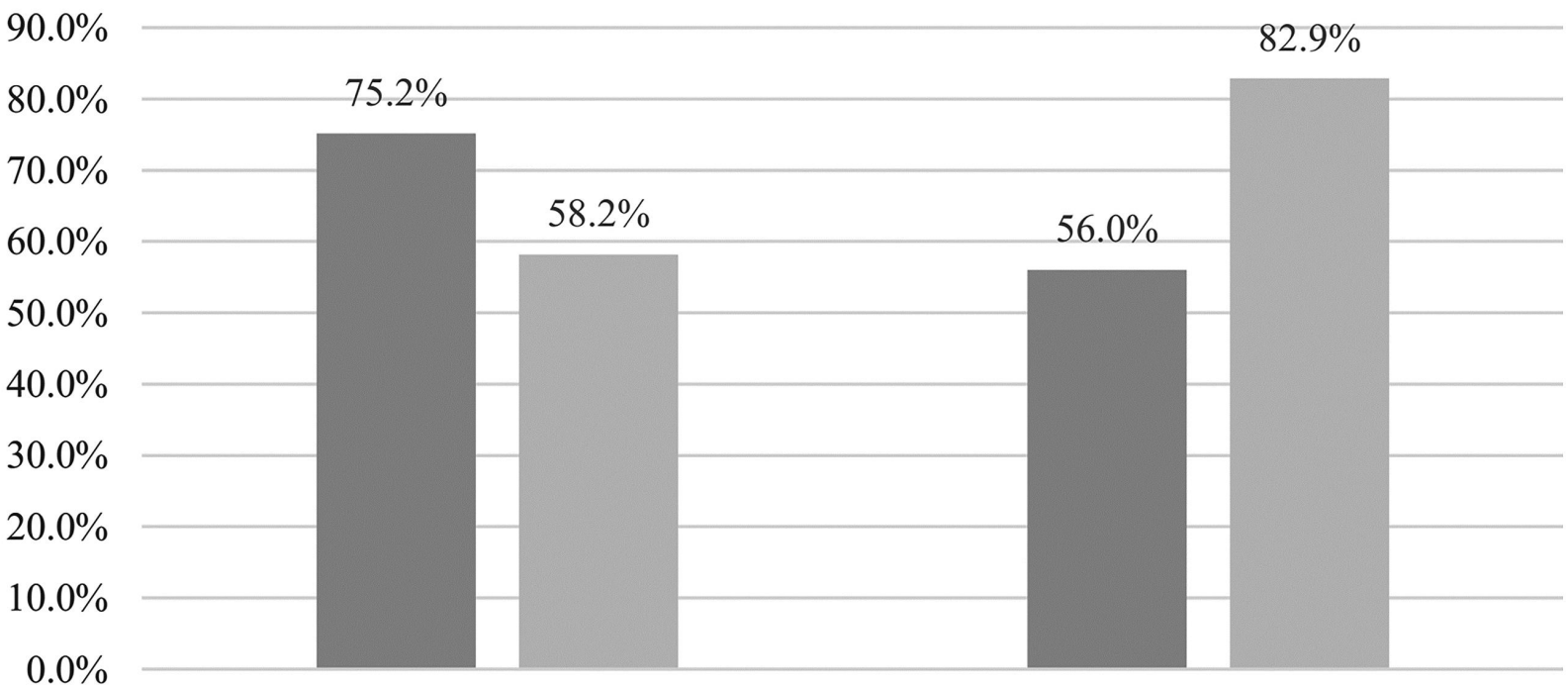

Albanian

English

\section{- Greek Vocabulary $\square$ Other Language Vocabulary}

Lastly, to determine vocabulary dominance we compared the size of Greek vocabulary to the size of the vocabulary in the other language for each bilingual. In order to standardize our data so that this comparison could take place, we turned vocabulary test scores into z-scores (i.e. standard scores). Subsequently, we subtracted the 'other' language's vocabulary zscore from the Greek vocabulary $z$-score; if the result was between -1 and +1 , an outcome which signifies vocabularies of comparable size, we considered the participant a balanced bilingual. If the result was higher than +1 , the participant was considered Greek dominant, while if the result was lower than -1 , then s/he was considered dominant in the other language. Most participants in both groups are balanced rather than Greek or Albanian/English dominant, with the difference between the two groups not being significant $(F(1,43)=4.029, p=.059)$. See Table 5 .

Table 5. Vocabulary dominance (\%).

\begin{tabular}{|l|c|c|}
\hline \multirow{2}{*}{ Vocabulary Dominance } & \multicolumn{2}{|c|}{ Groups } \\
\cline { 2 - 3 } & Albanian-Greek Bilinguals & English-Greek Bilinguals \\
\hline \hline Albanian/English dominant & 9.5 & 21.7 \\
\hline \hline Greek dominant & 19 & 30.4 \\
\hline \hline Balanced & 71.5 & 47.9 \\
\hline
\end{tabular}

\subsection{Predictions}

Considering (a) previous research findings on the role of input, early in life and currently, (b) the formal gender properties of the languages (gender marking available in Greek and Albanian in DPs but not in English) and (c) the different processes involved in gender assignment andgender agreement for real and pseudo-nouns, we formulate the following research hypotheses:

a. What are the effects of language external (input: amount of exposure to each language through a variety of measures for oral and written practices) and language internal factors (language proficiency) on the bilingual acquisition of Greek gender?

b. Are there differences in the bilingual acquisition of gender marking as regards real nouns (lexical knowledge required) and pseudo-nouns (morphophonological cues encoded on noun endings guiding speakers to the assignment of gender values)? Will language external (input measures) and language internal (vocabulary measure) factors affect real and pseudo-nouns similarly?

c. What is the role of the L1, namely whether L1 is a grammatical gender language (Albanian) or not (English), in the acquisition of Greek gender?

Given findings from previous studies on older bilingual children (cf. Meisel 2009; Unsworth etal. 2014), we predict that input measures of current exposure to Greek, like amount of current literacy exposure and current oral use of the language will be better predictors of gender accuracy than age of onset or early (pre-school) emergent literacy measures. Our second prediction concerns crosslinguistic influence from Albanian to Greek and lack thereof from English to Greek. ${ }^{4}$ Specifically, due to the differences between Albanian and English in grammatical gender (i.e. Albanian encodes grammatical gender but English does not) we predict that Albanian-Greek bilinguals will perform better on Greek gender assignment and agreement tasks compared to English-Greek bilinguals, over and above proficiency measures. Thirdly, regarding the comparison between performance on real and pseudo nouns, we formulate our predictions on the grounds that real nouns carry gender specification as part of their lexical entry while gender on pseudo-nouns needs to be determined on the basis of (un)ambiguous cues offered by the noun ending alone. We thus expect performance on gender assignment and agreement 
with real nouns to be affected by language proficiency considerably more than gender assignment and agreement with pseudo-nouns. Finally, possible SES differences between Albanian-Greek and English-Greek children are likely to have an effect on expressive vocabulary scores and, by extension, on gender performance with real nouns in particular.

\subsection{Results}

\subsubsection{Gender assignment}

To examine gender assignment in real and pseudo-nouns, we analysed data from the two determiner tasks. We performed repeated measures ANOVAs with bilingualism (bilinguals vs. monolinguals) and crosslinguistic influence, i.e. L1 effects (Albanian vs. English) as between subjects' variables. Figure 3 shows participant accuracy for real and pseudo-nouns.

Figure 3. Determiner task: total accuracy (\%).

100

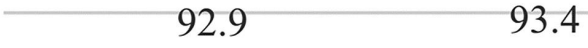

90

80

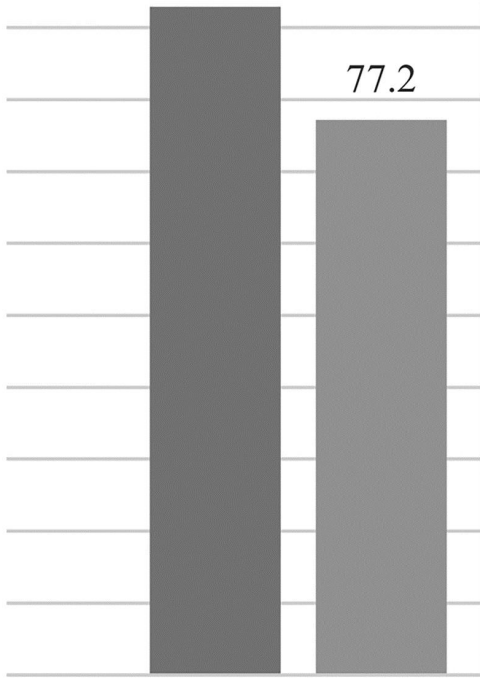

Real

84.8

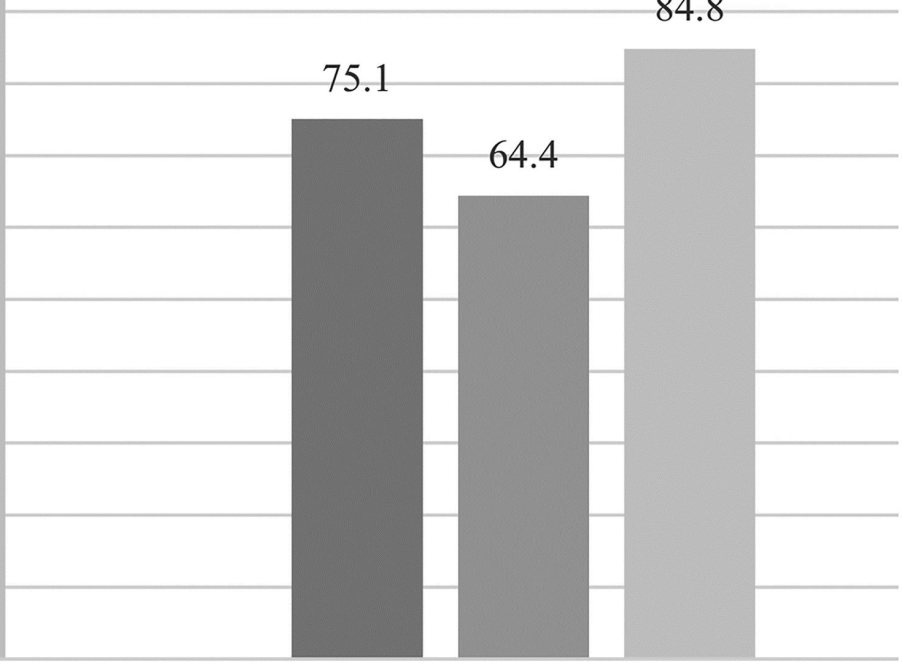

Pseudo

\section{albanian $\quad$ English $\square$ Controls}

With regard to real nouns the Albanian ${ }^{5}$ bilinguals did not differ from monolinguals. English bilinguals, however, scored significantly lower than the monolingual control group $(F(1,41)=19.021, p<.001)$. In pseudo-nouns both bilingual groups scored significantly lower than the monolinguals (Mono vs. Albanian: $F(1,43)=10.970, p=.002$; Mono vs. English: $F(1,41)=$ $19.843, p<.001)$. Last, when comparing the two bilingual groups, the Albanian bilinguals were shown to outperform the English group in both tasks (Real: $F(1,42)=11.180, p<.001$; Pseudo: $F(1,42)=4.442, p=.041$ ).

Next we examine the differences in accuracy for masculine, feminine and neuter items separately. For real nouns, within group three-way comparisons reveal that only monolingual children show a significant gender effect $(F(2,20)=3.970, p=.035)$ while in pseudo-nouns all three groups do (Albanian: $F(2,21)=28.827, p<.001$; English: $F(2,19)=20.168, p<.001$; Monolingual: $F(2,20)=96.284, p<.001)$. Post hoc tests using Bonferroni correction revealed that monolinguals performed significantly better in masculine than feminine nouns $(p=.041)$. For pseudo-nouns, post hoc tests showed that (a) Albanian bilinguals are more accurate with masculine than neuter and feminine items (Masc $>$ Neut $>$ Fem; Masc $>$ Neut, $p=.009$; Neuter $>$ Fem, $p=.002$; Masc $>$ Fem, $p<.001$ ), (b) English bilinguals perform better in the neuter and masculine pseudo-nouns while accuracy drops in feminine ones (Neut $>$ Fem, $p<.001$; Masc $>$ Fem, $p=.002$ ) while (c) monolinguals show the highest accuracy scores with masculine pseudo-nouns, with neuter following and with feminine showing the lowest scores (Masc $>$ Neut $>$ Fem; all pairings: $p<.001$ ). Figures $4-6$ show participant scores by gender value in real and pseudo-nouns.

Figure 4. Determiner task: masculine - accuracy (\%). 


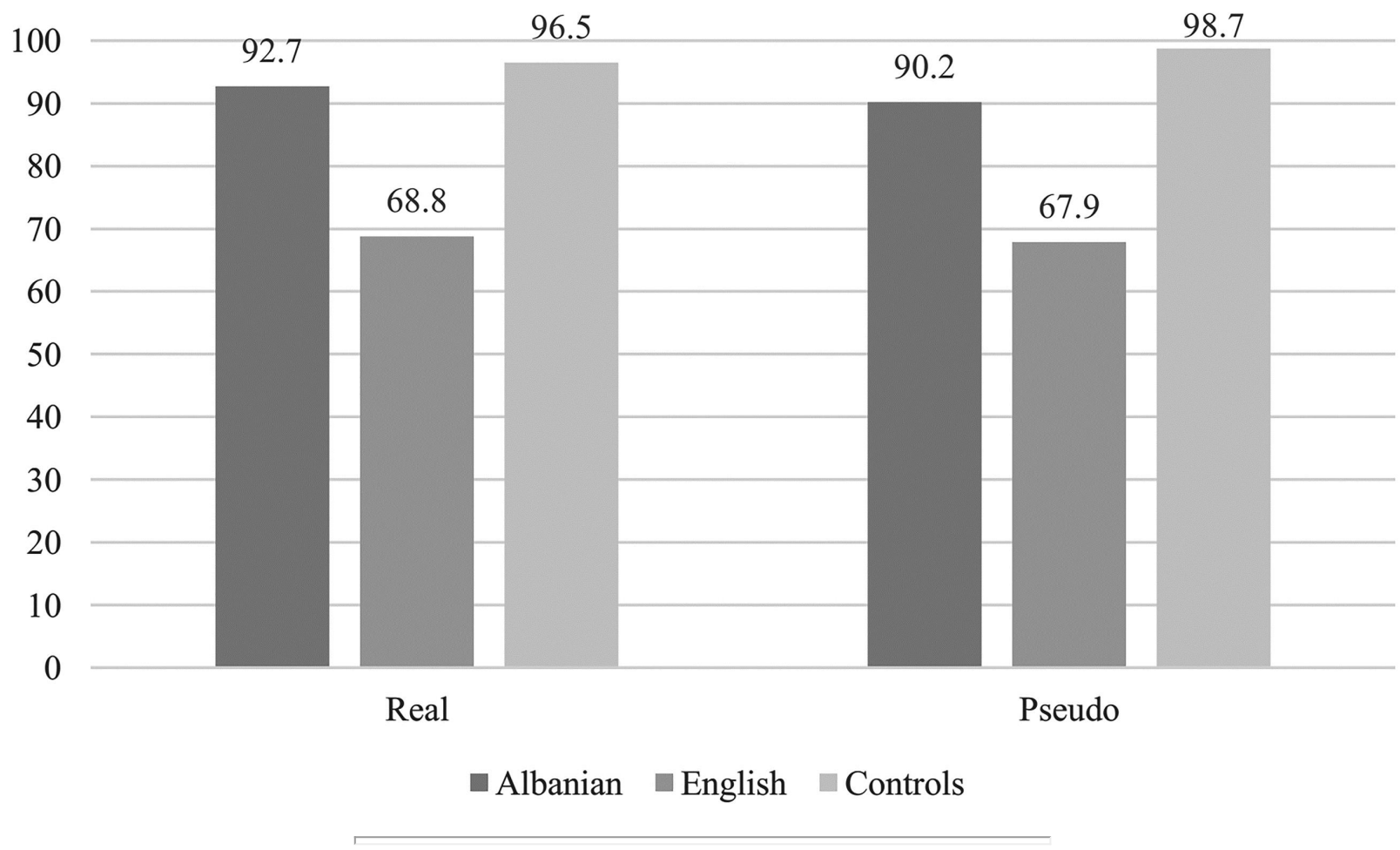

Figure 5. Determiner task: feminine - accuracy (\%).

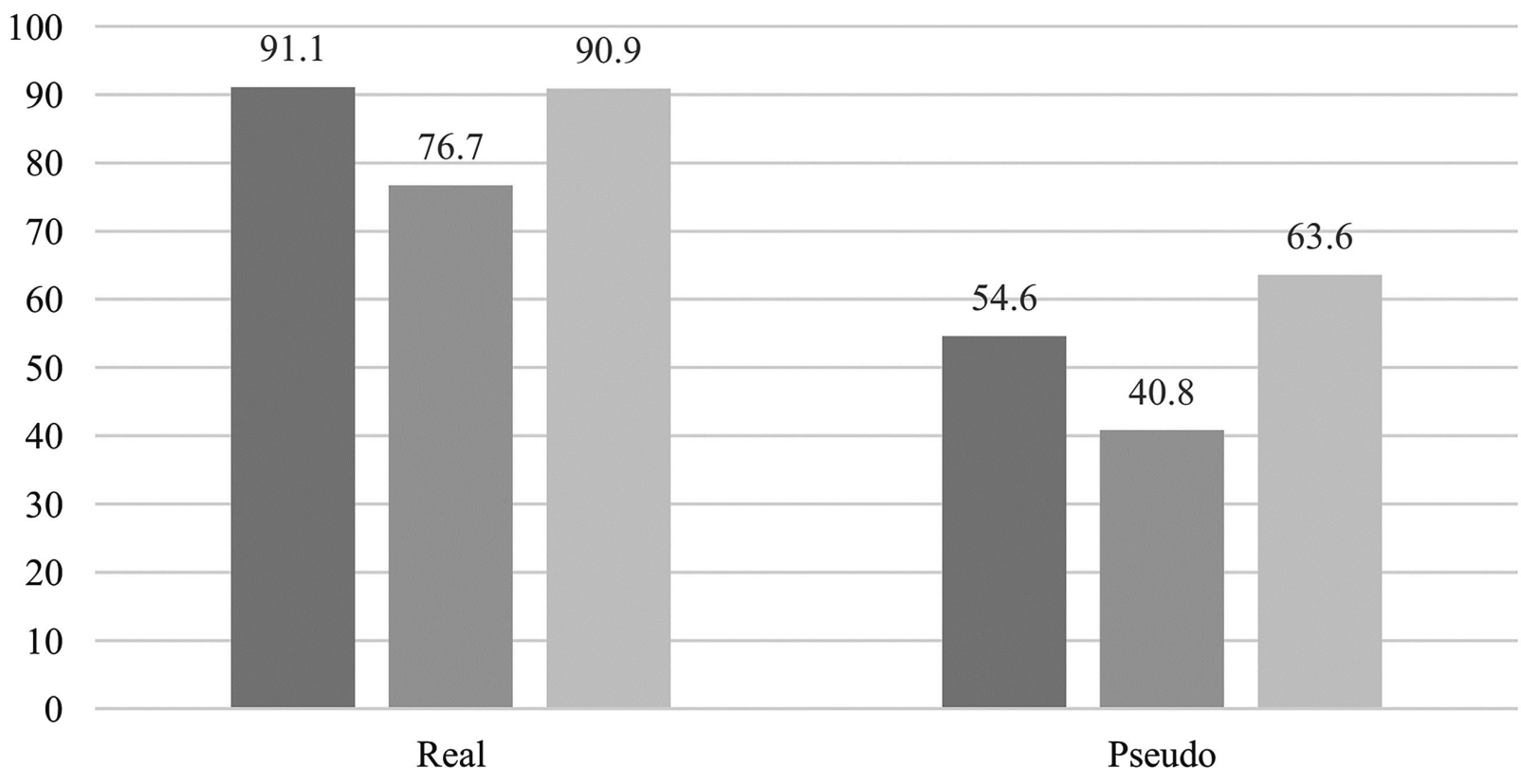

$\square$ Albanian $\square$ English $\square$ Controls

Figure 6. Determiner task: neuter - accuracy (\%). 


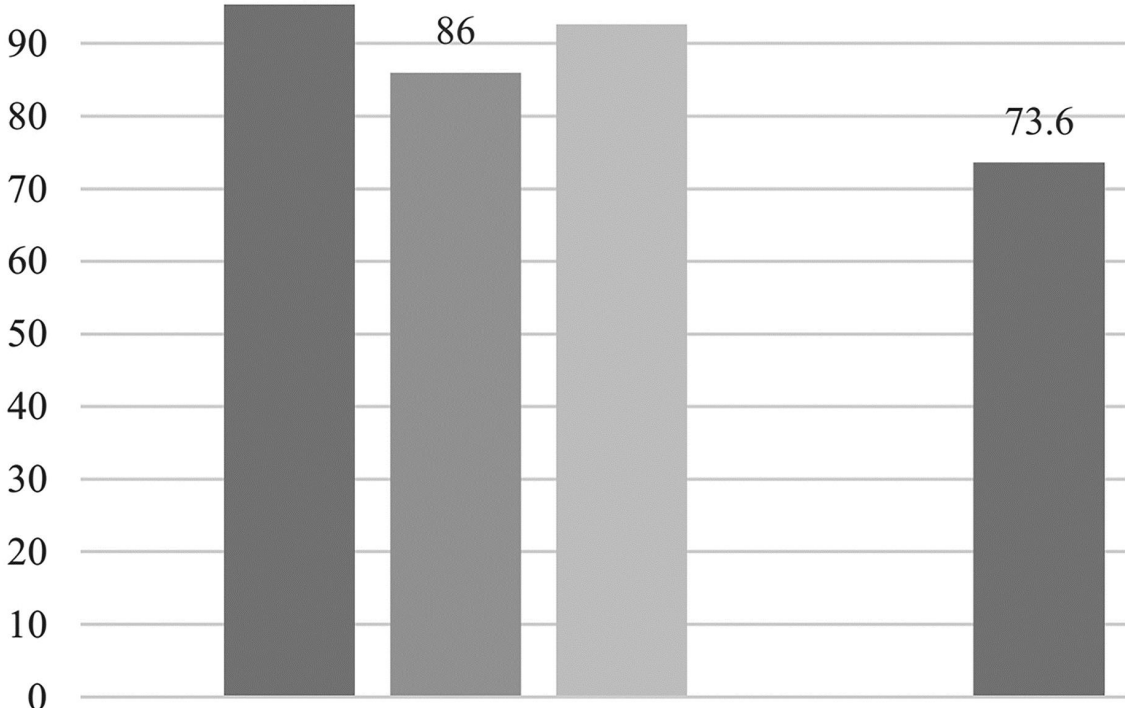

Real

\section{3}

85.2

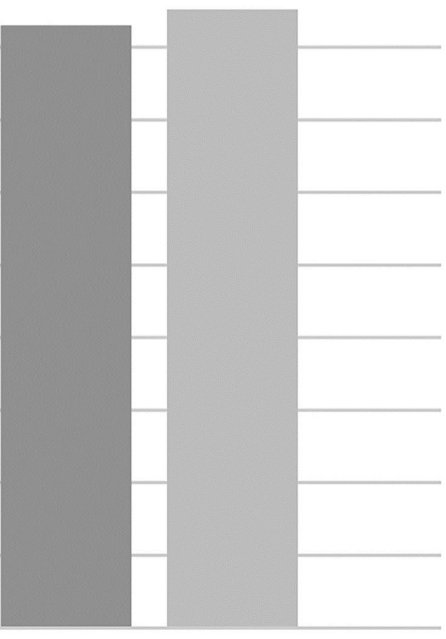

Pseudo

\section{$\square$ Albanian $\square$ English $\square$ Controls}

To further clarify group differences, we performed between group comparisons on group error data. Particularly, we tested the degree to which neuter, as the default gender, was used when gender production was inaccurate. In the real noun task, the English bilinguals erroneously overused neuter by $50 \%$ (130 out of 259 erroneous items), while the Albanian bilinguals only by $24 \%$ ( 21 out of 87 erroneous items); the between-group comparison showed a significant effect of neuter overuse by English bilinguals $\left(\mathrm{x}^{2}=17.975, \mathrm{df}=1, p<.001, \eta^{2}=.228\right)$. In the pseudo-noun task, English bilinguals overused neuter by $68 \%(284$ out of 418 erroneous items), while Albanian bilinguals by $54 \%$ (181 out of 331 erroneous items); the between-group comparison showed a significant effect of higher neuter overuse for English bilinguals $\left(x^{2}=13.797, \mathrm{df}=1, p<.001, \eta^{2}=.136\right)$. The error analysis on the overall performance in the two determiner tasks shows that English bilinguals systematically overuse neuter and this could be the reason why they outperform the Albanian bilinguals in the neuter nouns. Thus, accuracy scores on gender assignment suggest that Albanian bilingual children perform similarly to their monolingual peers while the English group lags behind with a specific error pattern, namely overusing neuter in the majority of error cases.

\subsubsection{Gender agreement}

To examine gender agreement in real and pseudo-nouns, we analyzed the accuracy scores from the two adjective tasks. We conducted repeated measures ANOVAs with bilingualism (bilinguals vs. monolinguals) and crosslinguistic influence, i.e. L1 effects (Albanian vs. English) as between subjects variables. Figure 7 shows participant total scores for predicate adjectives used with real and pseudo-nouns:

Figure 7. Adjective task: total accuracy (\%). 


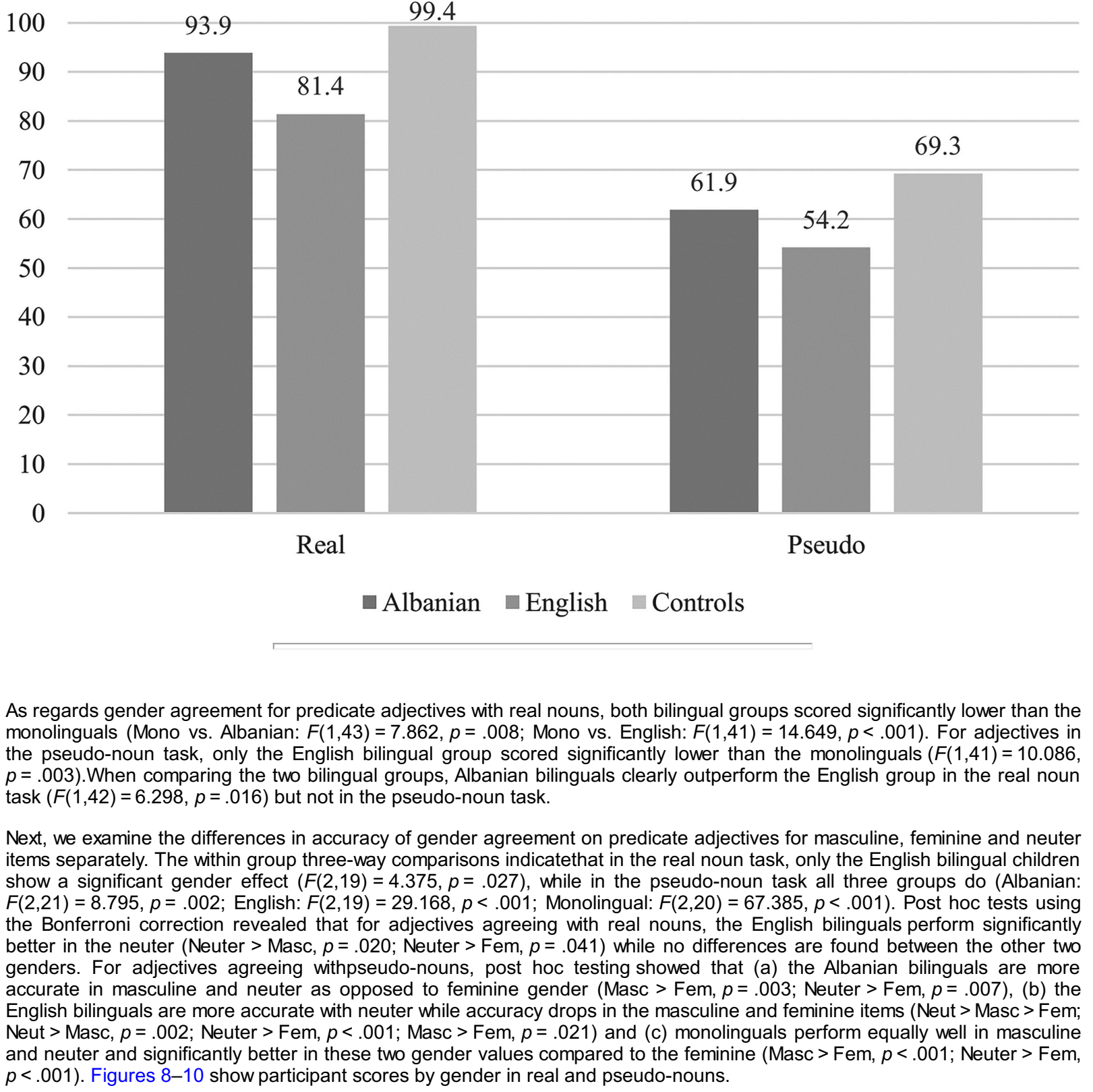
$p<.001$ ). Figures $8-10$ show participant scores by gender in real and pseudo-nouns.

Figure 8. Adjective task: masculine - accuracy (\%).

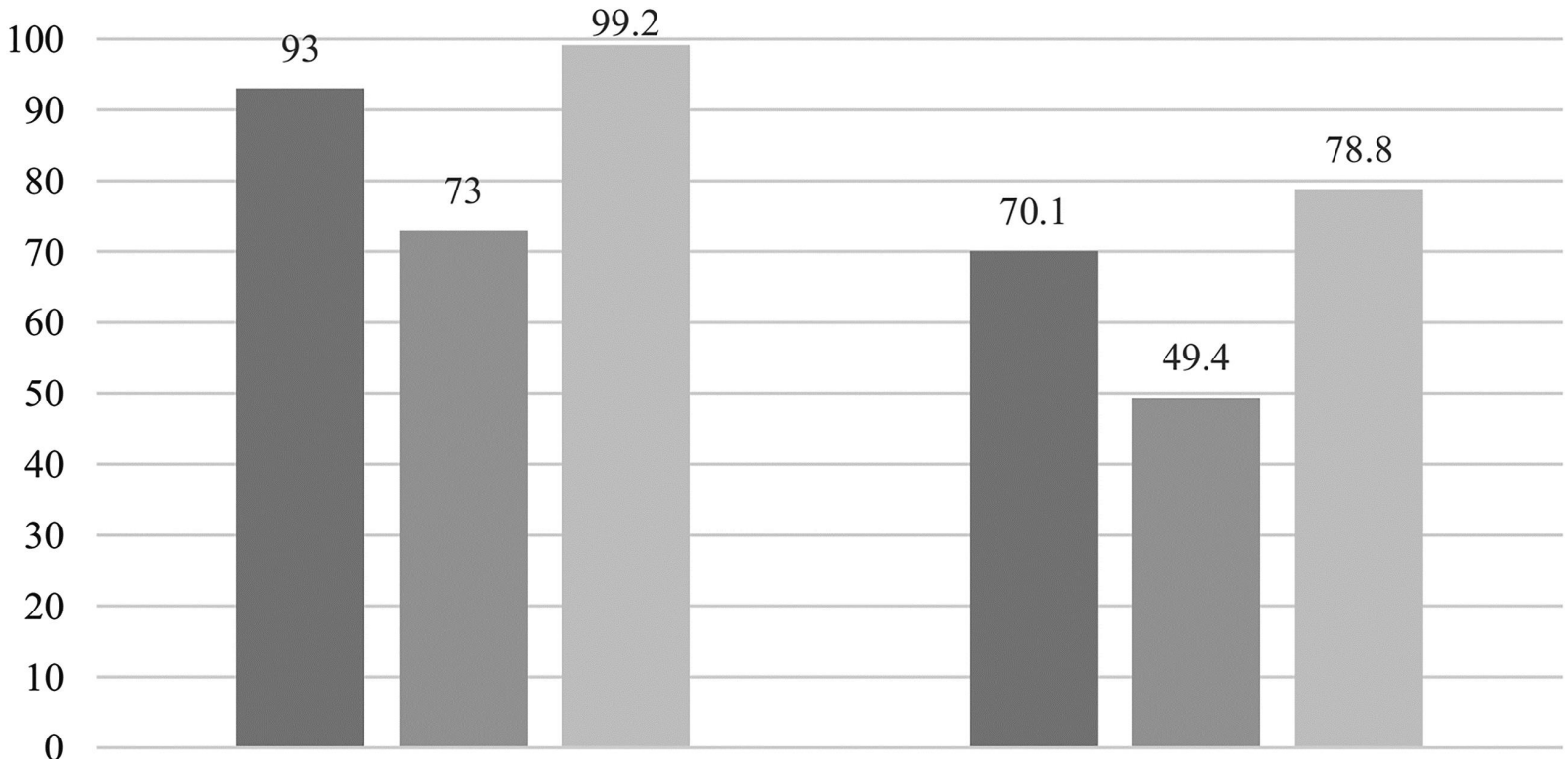

Real

Pseudo

albanian $\quad$ English $\square$ Controls 
Figure 9. Adjective task: feminine - accuracy (\%).

100

99

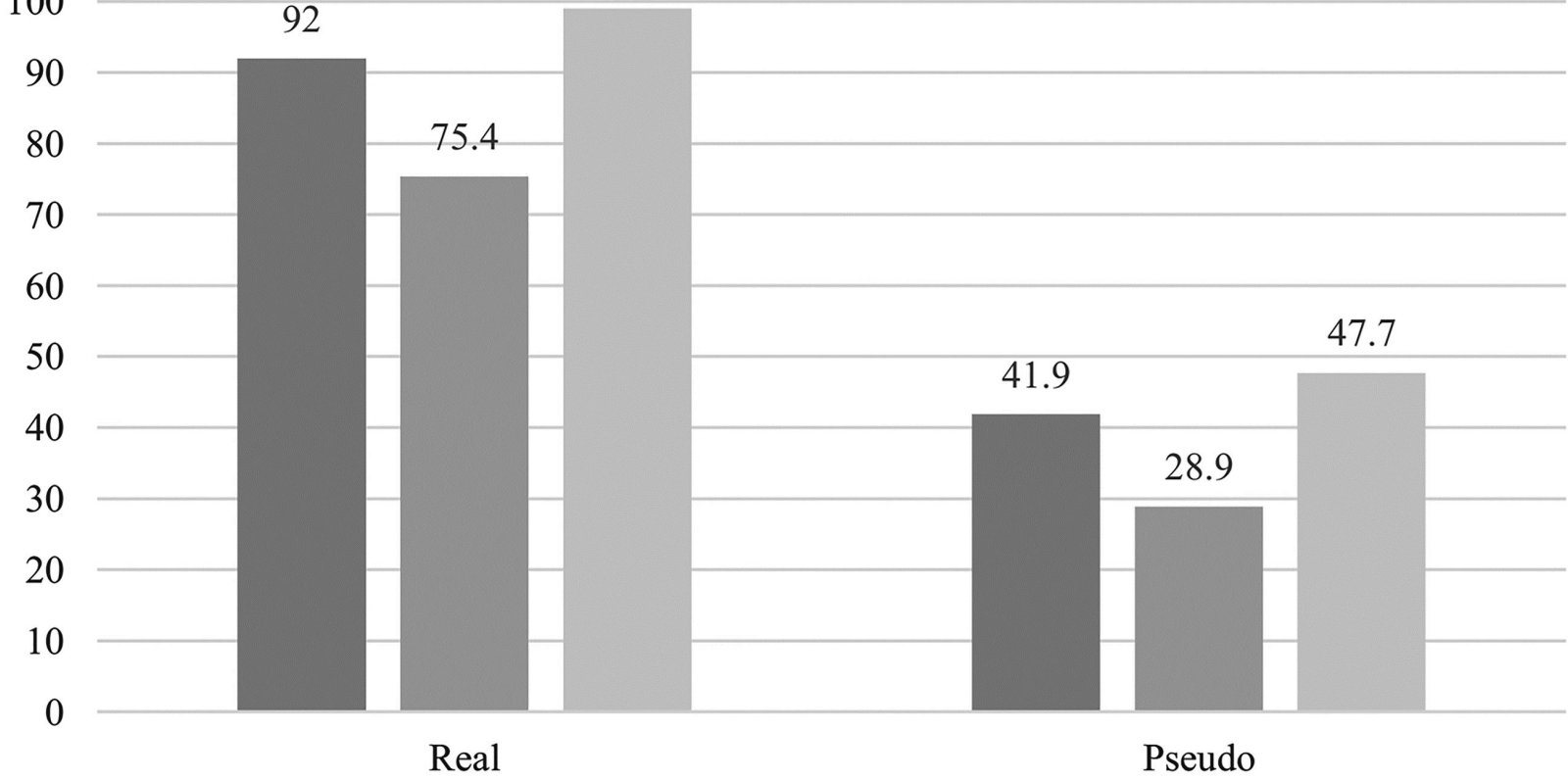

albanian $\square$ English $\square$ Controls

Figure 10. Adjective task: neuter - accuracy (\%).

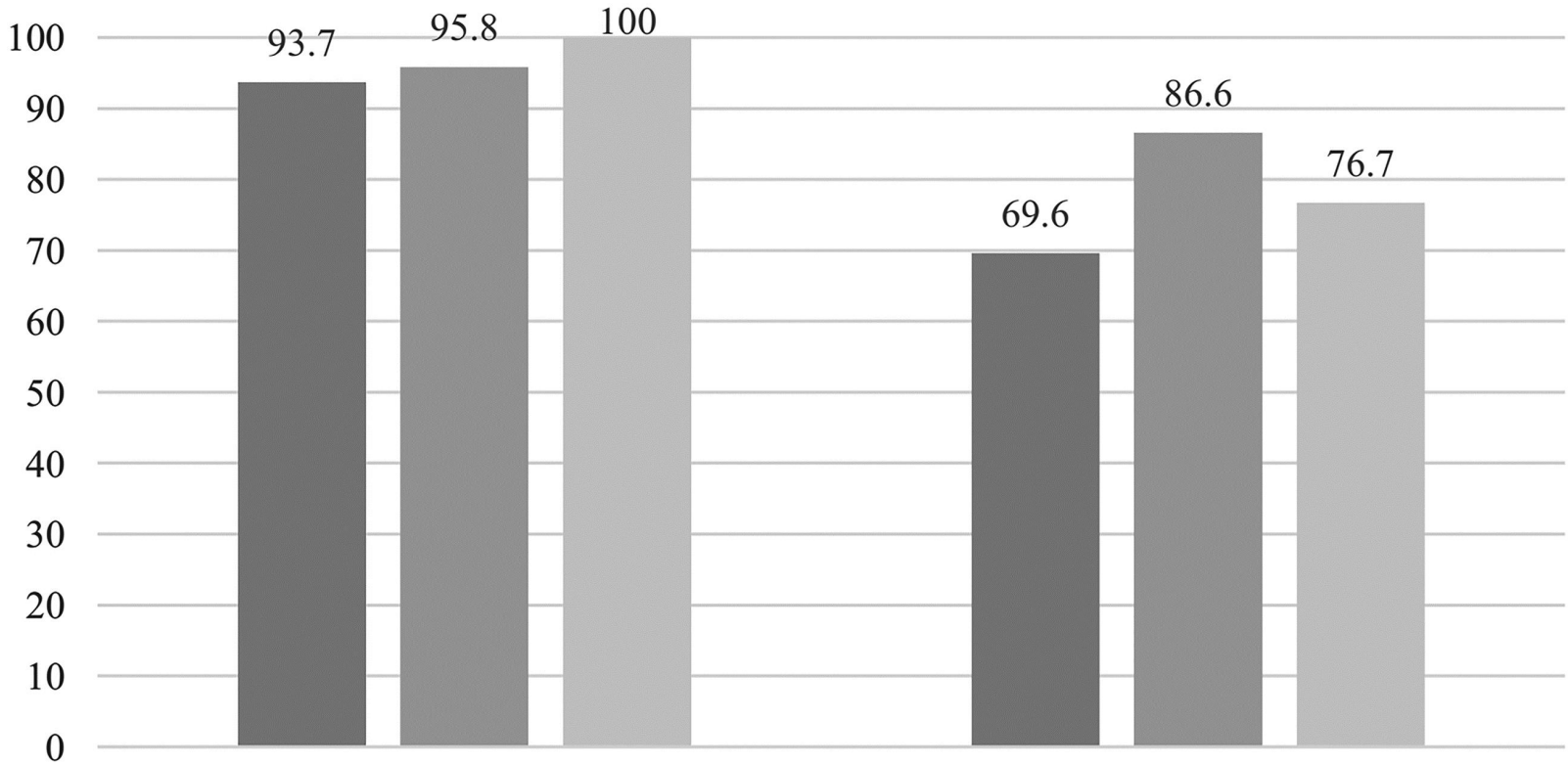

Real

Pseudo

albanian $\square$ English $\square$ Controls

To further evaluate differences in performance, we examined between group comparisons on participant error data. Similar to the determiner task, we tested the degree to which neuter was overused in cases of inaccurate production. In the real noun task, the English bilinguals overused neuter by $78 \%$ (165 out of 211 erroneous items), while the Albanian bilinguals by $62 \%$ (47 out of 75 erroneous items); the between group comparison showed a significant effect of neuter overuse by the English bilinguals $\left(\mathrm{X}^{2}=6.920, \mathrm{df}=1, p=.008, \eta^{2}=.156\right)$. In the pseudo noun task, the English bilinguals overused neuter by $81 \%(434$ out of 539 erroneous items), while the Albanian bilinguals by $57 \%$ (280 out of 491 erroneous items);again the between group comparison showed a significant effect of neuter overuse by the English bilinguals $\left(\mathrm{X}^{2}=66.681, \mathrm{df}=1, p<.001, \eta^{2}=.254\right)$. Error analysis on the overall performance in the two adjective tasks shows that the English bilinguals systematically overuse 
The data on gender agreement suggest that gender agreement between predicate adjective and noun or pseudo-noun were demanding for both bilingual groups, even though, similarly to the determiner tasks, the Albanian bilinguals outperformed the English bilinguals. To further investigate what drives this difference in performance, we looked for predictors for gender accuracy by considering input factors from current and previous language exposure in oral and literacy practices, and participant language proficiency, i.e. scores in vocabulary tests and language dominance measures.

\subsubsection{Predictors of gender accuracy}

A stepwise regression analysis 6 was performed on all experimental variables in order to test for significant predictor variables of the dependent variable, i.e. gender accuracy in gender assignment and agreement tasks. The variables (both language external and language internal factors) that entered the analysis were L1 effects, i.e. Albanian/English, Home Language (Gr, Other (Albanian/English), Both), Early Literacy (Yes/No), Early Literacy activities per Language (Gr, Other (Albanian/English), Both), Literacy Practices (Gr, Other (Albanian/English), Both), Current Language Use (Gr, Other (Albanian/English), Both), SES (mother's and father's level of education), Bilingual Type (Simultaneous, Early and Late Sequential), Biliteracy (Bilingual / Monolingual schooling), as well as language proficiency measures, i.e. Greek Vocabulary, Other Language (Albanian/English) Vocabulary, Language Dominance ( $\mathrm{Gr}$, Other (Albanian/English), Balanced). First, we will present results from overall accuracy scores and then results from the neuter items. Since neuter is the default gender value, we wanted to examine whether it will be affected by the same or different factors as the non-default forms.

\subsubsection{Overall accuracy scores}

Starting with gender assignment to real nouns, the resulting model (adjusted $R^{2}=.564, F(2,41)=28.757, p<.001$ ) explains $76.4 \%$ of the variance and includes Greek Vocabulary and Current Language Use of the Other Language as significant predictors of gender accuracy (Greek Vocabulary $\beta=.535, p<.001$, Tolerance $=0.811$, VIF $=1.233$, sr: .482 ${ }^{7}$; Current Language Use Other $\beta=-.36, p<.001$, Tolerance $=0.811, \mathrm{VIF}=1.233$, sr: -.324 ). Proficiency in Greek and current oral use of the other language can predict performance on gender real noun assignment in Greek in that the higher the bilingual's proficiency in Greek as measured by Greek Vocabulary, the higher the accuracy in the gender task, while the higher Current Language Use of the Other Language, the lower the gender accuracy in Greek. In gender agreement with real nouns, the resulting model (adjusted $R^{2}=.588, F(2,41)=31.648, p<.001$ ) explains $77.9 \%$ of the variance and includes the variables of Greek Vocabulary and Current Language Use of the Other Language as significant predictors of gender accuracy (Greek Vocabulary $\beta=.553, p<.001$ Tolerance $=0.811$, VIF $=1.233, s r=.498$; Current Language Use Other $\beta=-.359, p<.001$, Tolerance $=0.811, \mathrm{VIF}=1.233, s r=-.323$ ). The variables were found to function in the same way as in the gender assignment, i.e. while Greek Vocabulary accuracy predicts gender accuracy with real nouns with a positive direction, Current Language Use of the Other Language is inversely proportionate to accuracy. No other independent variables were shown to predict accuracy for real nouns.

Turning to gender assignment to pseudo nouns, the resulting model (adjusted $R^{2}=.388, F(2,41)=14.644, p<.001$ ) explains $64 \%$ of the variance and includes the variables of Greek Vocabulary andBilingual Type as significant predictors (Greek Vocabulary $\beta=.522, p<.001$, Tolerance $=0.926$, VIF $=1.080, s r=.503$; Bilingual Type $\beta=-.263, p<.05$, Tolerance $=0.926$, $\mathrm{VIF}=1.080, s r=.253)$. Proficiency in Greek and Bilingual Type can predict accuracy in gender assignment to pseudo-nouns since higher vocabulary scores and an early age of onset are associated with higher accuracy scores, thus showing that both language proficiency and exposure to the language at a younger age contribute to accuracy in gender assignment. The resulting model for the predicate adjective gender agreement with pseudo-nouns (adjusted $R^{2}=.365, F(3,40)=9.236$, $p<.001$ ) explains $64 \%$ of the variance and includes the variables of Current Language Use of the Other Language, Early Literacy and SES, in particular father's education, as significant predictors of gender accuracy (Current Language Use Other $\beta=-.548, p=.001$, Tolerance $=.857, \mathrm{VIF}=1.167, s r=-.507$; Early Literacy $\beta=.427, p=.004$, Tolerance $=.767, \mathrm{VIF}=1.303, s r$ $=.374$; SES father $\beta=.355, p=.02$, Tolerance $=.685$, VIF $=1.45, s r=.294$ ). The independent variables can predict the dependent variable in that the higher the rate of the Current Language Use of the Other Language, the lower the score in gender agreement accuracy for pseudo-nouns. On the other hand, higher SES levels (level of father's education) and Early Literacy lead to higher accuracy scores. In this respect, gender agreement with pseudo-nouns appears to be sensitive to input variables only, with the amount of the use of the other language being inversely proportionate to accuracy in the adjectivenoun gender agreement task. The analysis did not return any other significant predictor variables of the dependent variable.

Lastly, in order to further explore any possible L1 effects on accuracy, we conducted an additional analysis of group accuracy in the four gender tasks keeping the variable of Greek Vocabulary constant. However, L1 did not appear as a significant predictor of the dependent variable (Determiner - Real noun: $R^{2}$ change: $0.013, p>.05$; Adjective - Real noun: $R^{2}$ change: $0.00, p>.05$, Determiner - Pseudo-noun: $R^{2}$ change: $0.00, p>.05$, Adjective - Pseudo-noun: $R^{2}$ change: $0.009, p>.05$ ). Keeping constant the variable of Greek vocabulary, we further examined the effect of Biliteracy on the dependent variable. Inclusion of the variable of Biliteracy does not add significant predictive power after the variable of Greek Vocabulary was entered (Determiner - Real noun: $R^{2}$ change: 0.003, $p>.05$; Adjective - Real noun: $R^{2}$ change: 0.00, $p>.05$, Determiner Pseudo-noun: $R^{2}$ change: $0.00, p>0.05$, Adjective - Pseudo-noun: $R^{2}$ change: $0.059, p>0.05$ ). Overall, then, gender accuracy with real or pseudo-nouns seems to be primarily affected by vocabulary knowledge with the only exception being gender agreement accuracy with pseudo-nouns where input factors are exclusive predictors of performance.

\subsubsection{Neuter accuracy scores}

Starting with the gender assignment to real nouns, the resulting model (adjusted $R^{2}=.268, F(2,41)=8.861, p=.001$ ) explains $54.9 \%$ of the variance and includes the variables of Greek Vocabulary and Language Dominance as significant predictors (Greek Vocabulary $\beta=.482, p=.001$, Tolerance $=0.973$, VIF $=1.028, s r=.476$; Language Dominance $\beta=-.354, p<.05$, Tolerance $=0.973$, VIF $=1.028, s r=-.350$ ). As in the overall scores, higher Greek vocabulary scores are associated with higher task accuracy. The variable of Language Dominance, which was not found to affect the overall scores, can predict gender assignment in neuter nouns, since non-balanced participants, especially English/Albanian dominant ones, are more accurate with gender assignment on neuter items than balanced ones. With respect to gender agreement in the real noun task, the resulting model (adjusted $R^{2}=.077, F(1,42)=4.566, p<.05$ ) explains $31.3 \%$ of the variance and includes the variable of Language Dominance as the only significant predictor of the dependent variable $(\beta=-.313, p<.05$, Tolerance $=$ $1.00, \mathrm{VIF}=1.00, s r=-.313)$. As with gender assignment to real nouns, non-balanced participants dominant in the 'other' language fare better than balanced ones. This is an interesting, albeit counterintuitive, finding which indicates the different status of neuter compared to masculine and feminine nouns in Greek (see also Unsworth etal. 2014). 
Turning to pseudo-nouns, in the assignment task, the resulting model (adjusted $R^{2}=.121, F(1,42)=6.943, p<.05$ ), explains $37.7 \%$ of the variance and includes the variable of SES measured as father's education level as the only significant predictor of the dependent variable $(\beta=.377, p<.05$, Tolerance $=1.00, \mathrm{VIF}=1.00, \mathrm{sr}=.377)$. As in the overall pseudo scores, the higher the SES, the more accurate the performance. In the pseudo-noun agreement task the resulting model (adjusted $R^{2}$ $=.166, \mathrm{~F}(1,42)=9.544, p<.001)$ explains $43 \%$ of the variance and includes the variable of SES (father's education level) as the only significant predictor $(\beta=.430, p<.001$, Tolerance $=1.00, \mathrm{VIF}=1.00, s r=.377)$.

Table 6 summarizes the results of the regression analysis per task. The variables that are significant predictors of accuracy are presented with a tick $(\sqrt{ })$.

Table 6. Regression analysis - results summary.

\begin{tabular}{|c|c|c|c|c|c|c|c|c|}
\hline \multirow{3}{*}{ Input Variables } & \multicolumn{4}{|c|}{ Gender Assignment } & \multicolumn{4}{|c|}{ Gender Agreement } \\
\hline & \multicolumn{2}{|c|}{ Real } & \multicolumn{2}{|c|}{ Pseudo } & \multicolumn{2}{|c|}{ Real } & \multicolumn{2}{|c|}{ Pseudo } \\
\hline & Overall & Neut & Overall & Neut & Overall & Neut & Overall & Neut \\
\hline \multicolumn{9}{|l|}{ Language (L1) } \\
\hline Greek Voc & $\checkmark$ & $\checkmark$ & $\checkmark$ & & $\checkmark$ & & & \\
\hline \multicolumn{9}{|l|}{ Other Voc } \\
\hline Language Dominance & & $\checkmark$ & & & & $\checkmark$ & & \\
\hline \multicolumn{9}{|l|}{ Home Lg } \\
\hline Early Literacy & & & & & & & $\checkmark$ & \\
\hline \multicolumn{9}{|l|}{ Literacy Practices } \\
\hline \multicolumn{9}{|l|}{ Current Language Use - Greek } \\
\hline Current Language Use - Other & $\checkmark$ & & & & $\checkmark$ & & $\checkmark$ & \\
\hline \multicolumn{9}{|l|}{ Mother-SES } \\
\hline Father-SES & & & & $\checkmark$ & & & $\checkmark$ & $\checkmark$ \\
\hline Bilingual Type & & & $\checkmark$ & & & & & \\
\hline Biliteracy & & & & & & & & \\
\hline
\end{tabular}

\section{Discussion}

This study investigated gender assignment and gender agreement with real and pseudo-nouns in Greek by bilingual AlbanianGreek and English-Greek children 8-10 years old. The distinction between real and pseudo-nouns was motivated by the assumption that gender assignment and agreement with pseudo-nouns can only be triggered by the cue offered by the ending of the noun, whereas real noun gender assignment and agreement can also use lexical gender which is stored in the noun's lexical entry. As such, we expected the role of vocabulary knowledge to be more relevant to real rather than pseudo-nouns. In addition, the bilingual children differed not only with respect to whether their 'other' language marked grammatical gender on nouns (Albanian) or not (English) but also along other variables such as Greek vocabulary, age of onset of exposure to Greek, current language use, biliteracy levels, language dominance and SES.

As regards input variables, we hypothesized that measures of current literacy and current oral use of Greek will predict gender accuracy better than age of onset or early literacy measures. Moreover, given the distinct role of vocabulary and endings in the gender attribution process in real and pseudo nouns, we predicted that real nouns in both gender assignment and agreement tasks will be more affected by language proficiency scores (measured as vocabulary scores) than pseudo-nouns. Our findings reveal that bilingual children similarly to monolinguals are more accurate in assigning gender to real than to pseudo-nouns. Moreover, the role of language proficiency measured through expressive vocabulary scores is predictive of the performance on gender assignment and agreement with real nouns but only of the performance on gender assignment with pseudo-nouns, partly confirming our predictions that pseudo-nouns would be less sensitive to vocabulary knowledge. On the other hand, the role of vocabulary knowledge in gender assignment on real and pseudo-nouns suggests that bilingual children look for morpho-phonological cues on noun endings to access or discover the gender value of nouns or pseudo-nouns respectively. In real noun contexts the variance explained by vocabulary knowledge is $48.9 \%$, while in pseudo-nouns it is $50.3 \%$, as shown in section 4.4 in the regression results. Agreement in pseudo-noun contexts is inversely proportionate to the amount of oral use of the other language (Albanian/English), but directly proportionate to early literacy and the father's educational level. Finally, the amount of oral use of the other language was also found to be inversely proportionate to gender assignment and agreement with real nouns, yet not as decisively as language proficiency in Greek, as revealed by the results of the regression analysis. As regards L1 transfer effects, we predicted that Albanian-Greek bilinguals will be more aware of gender values in the Greek input, compared to English-Greek bilinguals, whose L1does not encode grammatical gender. The obtained data confirmed our hypothesis in that the Albanian-Greek bilingual group outperformed the English-Greek group in all tasks. The English-Greek bilingual group was found to overuse the default neuter more than the Albanian-Greek group. However, L1 effects were not found to be predictive of performance in any of the four conditions (gender assignment and agreement with real or pseudo-nouns). In this respect, the advantage attested in the Albanian-Greek bilingual group could reflect the overall better proficiency in Greek these children have, instead of a positive transfer effect of grammatical gender available in Albanian but not in English.

Our data show that bilingual acquisition of gender is affected primarily by language proficiency (expressive vocabulary) and less by input quantity measures or L1 transfer. Clearly, vocabulary development is closely linked to input effects itself; nevertheless, the variety of input factors that can contribute to its growth is considerable. In our study, input factors varied between early and current language exposure measures as well as oral and written input. The investigation of the contribution 
A similar line of reasoning was followed in Unsworth etal. (2014) where vocabulary was considered independently of measures of input, specifically cumulative input calculated on the basis of number of hours the child is exposed to each language on a daily basis (see Unsworth 2011).In the current study, the findings are consistent with Unsworth etal. (2014) insofar as the predictive role of vocabulary knowledge, a proxy for language proficiency, is concerned. The fact that gender assignment on pseudo-nouns is also predicted by Greek vocabulary scores, however, does not conform with our prediction. Recall that the prediction that gender on pseudo-nouns should not be as sensitive to vocabulary knowledge was partly based on the theoretical assumption that gender is lexically encoded in the noun's stem and spelled-out in the ending of the Greek noun. In the case of pseudo-nouns, however, no lexical gender is available for retrieval; hence the expectation was that lexical knowledge should not be as relevant to gender assignment with pseudo-nouns. Given that both vocabulary and age of onset appear to be the only significant predictors for gender assignment with pseudo-nouns, we suggest that generalizations concerning predictive values of noun endings are strengthened with better lexical skills in Greek (Tsimpli and Hulk 2013). Put differently, children with lower vocabulary scores have, however, stored the lexical gender feature and can thus retrieve and appropriately use it; on the other hand, it is only after vocabulary has reached a certain threshold level that learners are able to build expectations on the basis of morpho-phonological gender cues on the noun ending. This additional role of vocabulary in gender acquisition is also found in monolingual Greek-speaking children who show a delayed pattern of critical for the acquisition of gender in the L2 assignment for pseudo- compared to real nouns (Mastropavlou 2006). The present study suggests that the differential effect of vocabulary, i.e. through the contribution of lexical gender in the case of already acquired, real nouns on one hand, and the generalizations of predictive values of gender available through noun endings, on the other, is also attested in bilingual children's performance.

The only context in which vocabulary did not appear to play a predictive role is gender agreement with pseudo-nouns. In this context, quantity of input and specifically current oral use of the other language was inversely proportionate to gender accuracy. It has already been pointed out in the literature on gender acquisition that agreement between predicate adjectives and nouns is the most difficult and prone to error context for child second language learners (Konta 2013). Moreover, adjective-noun agreement in a predicate construction is structurally different and more complex than adjective-noun agreement within the DP causing more errors in adult second language learners too (Tsimpli etal. 2007). In our study, the complexity of the task increases further due to the adjective having to agree with a pseudo-noun. In this case, the gender value of the pseudo-noun is determined through a route different from that followed for gender assignment to a real noun, namely via the ending alone without the contribution of lexical gender stored with the noun stem itself (Ralli 2002). It is therefore likely that the negative effect of the use of the other language at the time of testing indicates that more complex and demanding syntactic structures are language-specific, resist positive transfer and depend more directly on input quantity (Tsimpli 2014).

Finally, the status of neuter gender as the default value for Greek is further supported by the data of the present study. There are two pieces of information that point to the different status of neuter compared to masculine and feminine. The first has to do with the different performance of the bilingual groups as regards gender. Albanian-Greek bilinguals appear not to overuse neuter to the same extent as English-Greek bilinguals (see section 4.4). The second piece of evidence comes from the accuracy scores on neuter real nouns which are predicted by language dominance in the unexpected direction, i.e. participants dominant in the 'other' language produce more accurate neuter nouns than balanced bilinguals. Recall that in terms of input variables, Albanian-Greek bilinguals differ as a group from English-Greek bilinguals in the type of bilingualism (the majority of Albanian-Greek children are simultaneous bilinguals; see section 4.2, Table 1 ) and in the number of children who are balanced bilinguals in that the majority of the Albanian-Greek children are balanced bilinguals (see section 4.2, Table 5). It could thus be suggested that the neuter overuse (instead of the appropriate masculine or feminine) and the higher accuracy in neuter nouns of English-Greek bilinguals and of bilinguals dominant in the other language stems from lower levels of exposure to Greek for whom neuter is the gender form used when gender is not really computed as such. Albanian-Greek bilinguals, being more sensitive to gender properties in Greek not only due to their L1 being a grammatical gender language but also due to more extensive Greek input resort to the default value considerably less than English-Greek bilinguals, often making errors with neuter nouns too.

\section{Conclusion}

The present study investigated bilingual children's performance on gender assignment and gender agreement with Greek real and pseudo-nouns and how it is affected by language proficiency (i.e. language internal factor) as well as by oral and written input in each language and current levels of oral and written language use in each language (i.e. language external factors). Most aspects of accuracy in gender performance are primarily explained by lexically-measured Greek proficiency scores with input factors predicting much less of the data. The contribution of vocabulary knowledge also accounts for gender assignment on pseudo-nouns supporting the claim that a certain threshold of lexical abilities must be reached for learners to develop sensitivity to predictive values of the cues that noun endings provide. The distinction between the default status of neuter gender compared to masculine and feminine values is further supported by this study in view of error patterns of neuter overuse in simultaneous vs. successive bilinguals as well as in view of L1 effects on neuter overuse.

Overall, the contribution of this study to research on child bilingualism is summarized in the relative role of language proficiency, L1 effects and input factors on grammatical gender performance in a language with rich grammatical gender cues. Specifically, the findings demonstrate the primary role of lexical skills and the minimal contribution of $L 1$ effects on gender performance. Input factors appear to only partially contribute to performance on gender agreement with nouns and more evidently with pseudo-nouns. We suggest that these findings support the view that grammatical gender is highly correlated with vocabulary knowledge on one hand and early exposure to Greek on the other. Therefore, it seems that lexical knowledge and input factors have a more significant impact on gender accuracy than L1 effects.

\section{Funding}

This work was co-financed by the European Union (European Social Fund - ESF) and the Greek national funds through the Operational Program 'Education and Lifelong Learning' of the National Strategic Reference Framework (NSRF) - Research Funding Program: Thales. Investing in knowledge society through the European Social Fund. Thales FP7 Project 'Bilingual Acquisition \& Bilingual Education: The Development of Linguistic \& Cognitive Abilities in Different Types of Bilingualism'(BALED - Award No MIS377313). PI: lanthi Maria Tsimpli. [COM1] This work was supported by the European Union[AQ5] [AQ6] [AQ7]Research Funding Program: Thales. Investing in knowledge society through the[AQ8]European Social Fund Thales FP7 Project 'Bilingual Aequisition \& Bilingual Edueation: The Development of Linguistic \& Cognitive Abilities in Different 
1. Throughout the paper, when presenting our dataset we use the term L1 to refer either to Albanian or English, depending on the bilingual pairing, and $\mathrm{L} 2$ to refer to Greek since for the majority of our participants that was the order of exposure to these languages.

2. See Ralli $(2005,119)$ for further details.

3. Suffixes -o, -as, -is, -o have high predictive values as far as gender is concerned, because they are clearly associated with one gender feature, while suffix $-i$ is associated with two gender features.

4. One reviewer noticed that, even though English does not mark grammatical gender, sex cues may be transferrable to Greek. However, our test items involve objects and animals and, thus, possible sex cues from English cannot be transferred into the gender of the Greek nouns.

5. In the results section (4.4) for brevity, Albanian-Greek bilinguals will be referred to as Albanian bilinguals and the English-Greek bilinguals as English bilinguals.

6. Lack of collinearity issues in our data, as confirmed by diagnostic tests conducted prior to the regression analysis, allowed us to proceed with the stepwise method.

7. Partial correlation scores (sr) show the individual contribution of each independent variable to the overall variance irrespective of the variance shared with other variables.

\section{Disclosure statement}

No potential conflict of interest was reported by the authors[AQ21].

\section{ORCID}

Maria Kaltsa http://orcid.org/0000-0002-2422-7889

\section{Reference[AQ22]s}

Armon-Lotem , S., J.Walters, and N.Gagarina. 2011. "The Impact of Internal and External Factors on Linguistic Performance in the Home Language and in L2 among Russian-Hebrew and Russian-German Preschool Children." Linguistic Approaches to Bilingualism 1: 291-317.

Blom , E. 2010. "Effects of Input on the Early Grammatical Development of Bilingual Children." International Journal of Bilingualism 14: 422-446.

Bošković , Z. 2009a. "Unifying First and Last Conjunct Agreement." Natural Language and Linguistic Theory 27 (3): $455-$ 496.

Bošković , Z. 2009b. “On Valued Uninterpretable Features.” Proceedings of NELS 39, Cornell.

Carroll , S. E. 1989. "Second-Language Acquisition and the Computational Paradigm." Language Learning 39: 535-594.

Carstens , V. 2000. "Concord in Minimalist Theory." Linguistic Inquiry 31: 319-355.

Chomsky, N. 1995. The Minimalist Program.. Cambridge, MA: The MIT Press.

Chomsky , N. 2001. "Derivation by Phase." In Ken Hale: A Life in Language, edited by M.Kenstovicz, 1-54. Cambridge, MA: The MIT Press.

Chondrogianni , V., and T.Marinis. 2011. "Differential Effects of Internal and External Factors on the Development of Vocabulary, Tense Morphology, and Morphosyntax in Successive Bilingual Children." Linguistic Approaches to Bilingualism 1: $318-345$.

Cobo-Lewis , A. B., B. Z.Pearson, R. E.Eilers, and V. C.Umbel. 2002. "Effects of Bilingualism and Bilingual Education on Oral and Written Spanish Skills: A Multifactor Study of Standardized Test Outcomes." In Language and Literacy in Bilingual Children, edited by D. K.Oller and R. E.Eilers. Clevedon: Multilingual Matters.[AQ24]

Corbett , G. 1991. Gender. Cambridge: Cambridge University Press.

Cornips , L., and A.Hulk. 2006. "External and Internal Factors in Bilingual and Bidialectal Language Development: Grammatical Gender of the Dutch Definite Determiner." In L2 Acquisition and Creole Genesis: Dialogues, edited by C.Lefebvre, L.White, and C.Jourdan. Amsterdam: JohnBenjamins.

Cornips , L., M.van der Hoek, and R.Verwer. 2006. "The Acquisition of Grammaticalgender in Bilingual Child Acquisition of Dutch (By Older Moroccan and Turkish Children)." In The Definite Determiner, Attributive Adjective and Relative Pronoun, edited by B.Los and J.van de Weijer, 40-51. Linguistics-in-The Netherlands.

De Houwer , A. 2007. "Parental Language Input Patterns and Children's Bilingual Use." Applied Psycholinguistics 28: 411424. 
Gathercole , V.C.M. 2002a. "Command of the Mass/Count Distinction in Bilingual and Monolingual Children: An Englishmorphosyntactic Distinction." In Language and Literacy in Bilingual Children, edited by D. K.Ollerand and R.E.Eilers. Clevedon: Multilingual Matters.

Gathercole , V.C.M. 2002b. "Grammatical Gender in Bilingual and Monolingual Children: A Spanish Morphosyntactic Distinction." In Language and Literacy in Bilingual Children, edited by D. K.Oller and R. E.Eilers. Clevedon: Multilingual Matters.

Gathercole , V.C.M. 2002c. "Monolingual and Bilingual Acquisition: Learning Different Treatments of That-Trace Phenomena in English and Spanish." In Language and Literacy in Bilingual Children, edited by D. K.Oller and R. E.Eilers. Clevedon: Multilingual Matters.

Gathercole , V.C.M., and E. M.Thomas. 2005. "Minority Language Survival: Input Factors Influencing the Acquisition of Welsh." In Proceedings of the 4th International Symposium on Bilingualism, edited by J.Cohen, K.McAlister, K.Rolstad, and J.MacSwan. Somerville, MA: Cascadilla Press.

Genesee , F., and E.Nicoladis. 2007. "Bilingual First-Language Acquisition." In Handbook of Language Development, edited by E.Hoff and P.McCardle. Oxford: Blackwell.

Gertken , L., M.Amengual, and D.Birdsong. 2014. "Assessing Language Dominance with the Bilingual Language Profile." In Measuring L2 Proficiency: Perspectives from SLA, edited by P.Lerclercq, A.Edmonds, and H.Hilton, 208-225. Bristol: Multilingual Matters.

Goldberg , H., J.Paradis, and M.Crago. 2008. "Lexical Acquisition Over Time in Minority L1 Children Learning English as L2." Applied Psycholinguistics 29: 41-65.

Hawkins, R., and I. M.Tsimpli. 2009. "Explaining Target- and Non-Target Performance in the Acquisition of Gender Concord by L2 Speakers." Paper presented at ISB7, Utrecht, July 2009.

Hulstijn , J. H. 2010. "Measuring Second Language Proficiency." In Experimental Methods in Language Acquisition Research, edited by E.Bloom and S.Unsworth, 185-200. Amsterdam: Benjiamins.

Jia , G., and A.Fuse. 2007. "Acquisition of English Grammatical Morphology by Native Mandarin-Speaking Children and Adolescents: Age-Related Differences.” Journal of Speech Language and Hearing Research 50: 1280-1299.

Kapia , E., and A.Kananaj. 2013. The Albanian Vocabulary Instrument. Tiranë: Center for Albanian Studies, Institute of Linguistics and Literature.

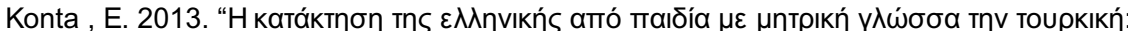

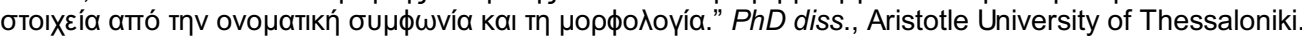

Kupisch , T. 2005. "Acceleration in Bilingual First Language Acquisition." In Languages and Linguistic Theory, Selected Papers from Going Romance 2003, edited by TwanGaerts, IvoVan Ginneken, and HaikeJacobs, 143-157. Amsterdam: John Benjamins.

Kupisch , T. 2007. "Determiners in Bilingual German-Italian Children: What They Tell Us About the Relation Between Language Influence and Language Dominance." Bilingualism: Language and Cognition 10 (1): 57-78.

Kupisch , T., N.Müller, and K. F.Cantone. 2002. "Gender in Monolingual and Bilingual First-Language Acquisition." Lingue e Linguaggio 1: 107-150.

Kurani , A., and A.Muho. 2011. "A Morphological and Comparative Study Between Albanian and English Language." European Scientific Journal 14: 28-47.

Kurani , A., and A.Trifoni. 2014. "Syntactic Similarities and Differences Between Albanian and English." European Scientific Journal 14: 47-62.

La Morgia , F. 2011. "Bilingual First-Language Acquisition: The Nature of the Weak Language and the Role of the Input." PhD diss., Dublin City University.

Marinis , T. 2003. The Acquisition of the DP in Modern Greek. Amsterdam: J. Benjamins Publishers.

Mastropavlou , M. 2006. "The Role of Phonological Salience and Feature Interpretability in the Grammar of Typically Developing and Language-Impaired Children.” PhD diss., Aristotle University of Thessaloniki.

Mastropavlou , M., and I. M.Tsimpli. 2011. "The Role of Suffixes in Grammatical Gender Assignment in Modern Greek: A Psycholinguistic Study." Journal of Greek Linguistics 11: 27-55. 
Meisel , J. M. 2009. "Second-Language Acquisition in Early Childhood." Zeitschrift Für Sprachwissenschaft 28: 5-34.

Montrul , S. A. 2016. "Dominance and Profociency in Early and Late Bilingualism." In Language Dominance in Bilinguals: Issues of Measurement and Operationalization, edited by C.Silva-Corvalan and J.Treffers-Daller, 15-35. Cambridge University Press.

Aontrul, S. A., R.Foote, and S.Perpiñán. 2008. "Gender Agreement in Adult Second Language Learners and Spanish Heritage Speakers: The Effects of Age and Context of Acquisition." Language Learning 58: 503- 553.

Montrul , S., and K.Potowski. 2007. "Command of Gender Agreement in School-Age Spanish-English Bilingual Children." International Journal of Bilingualism 11: 301-328.

Müller , N. 1990. "Developing Two Gender-Assignment Systems Simultaneously." In Two First Languages: Early Grammatical Development in Bilingual Children, edited by J. M.Meisel. Dordrecht: Foris.

Müller , N. 1998. “Transfer in Bilingual First Language Acquisition.” Bilingualism: Language and Cognition 1 (3): 151-171.

Müller , N., and A.Hulk. 2001. "Crosslinguistic Influence in Bilingual Language Acquisition: Italian and French as Recipient Languages." Bilingualism: Language and Cognition 4 (1): 1-21.

Nicoladis, E. 2006. "Cross-Linguistic Transfer in Adjective-Noun Strings by Preschool Bilingual Children." Bilingualism: Language and Cognition 9: 15-32.

Paradis , J. 2010. "Bilingual Children's Acquisition of English Verb Morphology: Effects of Languageexposure, Structure Complexity, and Task Type." Language Learning 60: 651-680.

Paradis , J. 2011. "Individual Differences in Child English Second-Language Acquisition: Comparing Child-Internal and ChildExternal Factors." Linguistic Approaches to Bilingualism 1: 213-237.

Paradis , J., and F.Genesee. 1996. "Syntactic Acquisition in Bilingual Children: Autonomous or Independent?" Studies in Second Language Acquisition 18: 1-25.

Place , S., and E.Hoff. 2011. "Properties of Dual Language Exposure That Influence Two-Year-Olds' Bilingual Proficiency." Child Development 82: 1834-1849.

Ralli , A. 2002. “The Role of Morphology in Gender Determination: Evidence from Modern Greek.” Linguistics 40: $183-551$.

Renfrew, C. E. 2001. Word Finding Vocabulary Test. 4th ed. Bicester: Speechmark.

Revithiadou , A., and V.Spyropoulos. 2013. A Comparative Study of Albanian-Greek Grammatical Structures. Project 'Education of Immigrant and Repatriate Students' Operational Program of Education and Lifelong Learning (NSRF 20072013). Thessaloniki: Aristotle University of Thessaloniki Publications, Research Committee. $\mathrm{http} / / / \mathrm{wmw}$.diapolis.auth.gr/index.php/2013-10-17-09-02-51/-52.

Stephany , U. 1997. "The Acquisition of Greek." In The Cross-Linguistic Study of Language Acquisition. Vol. 4, edited by D. I.Slobin, 183-333. Hillsdale, NJ: Erlbaum.

Stephany , U., and A.Christofidou. 2008. The Acquisition of Greek Case, Number, and Gender: A Usage-Based Approach. Arbeitspapier 55 (Neue Folge). Allgemeine Sprachwissenschaft, University of Cologne.

Tsimpli , I. M. 2003. "Features in L1 and L2 Acquisition: Evidence from Greek Clitics and Determiners." Acquisition et Interaction en Langue Étrangère 20: 87-128.

Tsimpli , I. M. 2014. "Early, Late or Very Late? Timing Acquisition and Bilingualism." Linguistic Approaches to Bilingualism 4 (3): 283-313.

Tsimpli , I., and A.Hulk. 2013. "Grammatical gender and the notion of default: Insights from language acquisition." Lingua 137: 128-144.

Tsimpli , I. M., A.Roussou, G.Fotiadou, and M.Dimitrakopoulou. 2007. "The Syntax-Morphology Interface. Agree Relations in L1 Slavic/ L2 Greek." Proceedings of the 7th international conference on Greek linguistics (ICGL7), University of York.

Unsworth , S. 2011. “Utrecht Bilingual Language Exposure Calculator.” Unpublished Manuscript.

Unsworth , S. 2013. "Assessing the Role of Current and Cumulative Exposure in Simultaneous Bilingual Acquisition: The Case of Dutch Gender." Bilingualism: Language and Cognition 16: 86-110. 
Unsworth , S. 2016. "Amount of Exposure as a Proxy for Dominance in Bilingual Language Acquisition." In Language Dominance in Bilinguals: Issues of Measurement and Operationalization, edited by C.Silva-Corvalan and J.Treffers-Daller, 156-173. Cambridge University Press.

Unsworth , S., F.Argyri, L.Cornips, A.Hulk, A.Sorace, and I. M.Tsimpli. 2014. "The Role of Age of Onset and Input in Early Child Bilingualism in Greek and Dutch." Applied Psycholinguistics 35 (4): 765-805.

Varlokosta , S. 2011. "The Role of Morphology in Grammatical Gender Assignment: A Psycholinguistic Study in Greek." In Morphology and Its Interfaces, edited by A.Galani, G.Hicks, and G.Tsoulas. Amsterdam: John Benjamins.

Vogindroukas , I., A.Protopapas, and G.Sideridis. 2009. Experiment on the Expressive Vocabulary (Greek Version of Renfrew Word Finding Vocabulary Test). Chania: Glafki. 